\title{
An analytical inversion method for determining regional and global emissions of greenhouse gases: Sensitivity studies and application to halocarbons
}

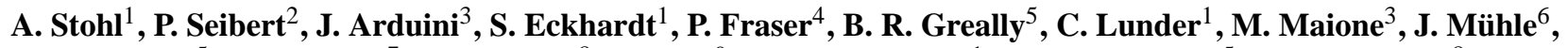 \\ S. O'Doherty ${ }^{5}$, R. G. Prinn ${ }^{7}$, S. Reimann ${ }^{8}$, T. Saito ${ }^{9}$, N. Schmidbauer ${ }^{1}$, P. G. Simmonds ${ }^{5}$, M. K. Vollmer ${ }^{8}$, R. F. Weiss ${ }^{6}$, \\ and Y. Yokouchi ${ }^{9}$ \\ ${ }^{1}$ Norwegian Institute for Air Research, Kjeller, Norway \\ ${ }^{2}$ Institute of Meteorology, University of Natural Resources and Applied Life Sciences, Vienna, Austria \\ ${ }^{3}$ University of Urbino, Urbino, Italy \\ ${ }^{4}$ Centre for Australian Weather and Climate Research, CSIRO Marine and Atmospheric Research, Aspendale, Australia \\ ${ }^{5}$ School of Chemistry, University of Bristol, Bristol, UK \\ ${ }^{6}$ Scripps Institute of Oceanography, University of California, San Diego, CA, USA \\ ${ }^{7}$ Center for Global Change Science, Massachusetts Institute of Technology, Cambridge, MA, USA \\ ${ }^{8}$ Swiss Federal Laboratories for Materials Testing and Research (Empa), Duebendorf, Switzerland \\ ${ }^{9}$ National Institute for Environmental Studies, Tsukuba, Japan
}

Received: 5 September 2008 - Published in Atmos. Chem. Phys. Discuss.: 13 November 2008

Revised: 16 February 2009 - Accepted: 19 February 2009 - Published: 3 March 2009

\begin{abstract}
A new analytical inversion method has been developed to determine the regional and global emissions of long-lived atmospheric trace gases. It exploits in situ measurement data from three global networks and builds on backward simulations with a Lagrangian particle dispersion model. The emission information is extracted from the observed concentration increases over a baseline that is itself objectively determined by the inversion algorithm. The method was applied to two hydrofluorocarbons (HFC-134a, HFC-152a) and a hydrochlorofluorocarbon (HCFC-22) for the period January 2005 until March 2007. Detailed sensitivity studies with synthetic as well as with real measurement data were done to quantify the influence on the results of the a priori emissions and their uncertainties as well as of the observation and model errors. It was found that the global a posteriori emissions of HFC-134a, HFC-152a and HCFC-22 all increased from 2005 to 2006. Large increases $(21 \%, 16 \%$, $18 \%$, respectively) from 2005 to 2006 were found for China, whereas the emission changes in North America (-9\%, 23\%, $17 \%$, respectively) and Europe $(11 \%, 11 \%,-4 \%$, respectively) were mostly smaller and less systematic. For Europe, the a posteriori emissions of HFC-134a and HFC-152a were
\end{abstract}

slightly higher than the a priori emissions reported to the United Nations Framework Convention on Climate Change (UNFCCC). For HCFC-22, the a posteriori emissions for Europe were substantially (by almost a factor 2) higher than the a priori emissions used, which were based on HCFC consumption data reported to the United Nations Environment Programme (UNEP). Combined with the reported strongly decreasing HCFC consumption in Europe, this suggests a substantial time lag between the reported time of the HCFC22 consumption and the actual time of the HCFC-22 emission. Conversely, in China where HCFC consumption is increasing rapidly according to the UNEP data, the a posteriori emissions are only about $40 \%$ of the a priori emissions. This reveals a substantial storage of HCFC-22 and potential for future emissions in China. Deficiencies in the geographical distribution of stations measuring halocarbons in relation to estimating regional emissions are also discussed in the paper. Applications of the inversion algorithm to other greenhouse gases such as methane, nitrous oxide or carbon dioxide are foreseen for the future.

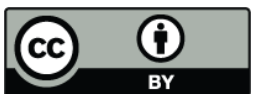

Correspondence to: A. Stohl

(ast@nilu.no)

Published by Copernicus Publications on behalf of the European Geosciences Union. 


\section{Introduction}

Over the past few decades, halocarbons have been used for refrigeration, as solvents, aerosol propellants, for foam blowing and for many other applications. Halocarbons containing chlorine and bromine lead to the depletion of ozone in the stratosphere (Chipperfield and Fioletov, 2007) and, therefore, their usage has been regulated under the Montreal Protocol on Substances that Deplete the Ozone Layer. As a consequence, chlorofluorocarbon (CFC) emissions have decreased considerably in recent years, but the emissions of hydrochlorofluorocarbons (HCFCs, used as interim replacement compounds for CFCs) are still growing in some countries. Hydrofluorocarbons (HFCs) are being used as replacement compounds for most long-lived halocarbons containing chlorine and bromine and their emissions are increasing. Consequently, atmospheric concentrations of the more abundant HFCs (HFC-125, HFC-134a, HFC-152a) have been growing by about $10-14 \%$ per year (Forster et al., 2007b; Reimann et al., 2008; Greally et al., 2007; Clerbaux and Cunnold, 2007). While HFCs pose no danger for stratospheric ozone, they are effective greenhouse gases (GHGs). Thus, there is considerable interest in their emissions and they are included in the Kyoto Protocol to the United Nations Framework Convention on Climate Change.

Halocarbon emissions can be determined using production, sales and consumption data such as provided by industry through the Alternative Fluorocarbons Environmental Acceptability Study (AFEAS, 2007) (http://www.afeas.org/), by the Technology and Economic Assessment Panel of the UNEP/IPCC (TEAP, 2005), or as reported in a number of other studies (e.g., McCulloch et al., 2003; Ashford et al., 2004b). The emissions can also be determined from atmospheric measurement data in conjunction with an atmospheric transport model that relates emissions to atmospheric concentrations, and an inversion algorithm. The inversion algorithm adjusts the emissions used in the model to optimize the agreement between the observed and the simulated concentrations. For estimating halocarbon or methane sources, Hartley and Prinn (1993) and Chen and Prinn (2006) used a global chemistry transport model and a linear Kalman filter, Mulquiney et al. (1998) a global Lagrangian model and a Kalman filter, Mahowald et al. (1997) a global chemistry transport model and a recursive weighted least-squares optimal estimation method. The spatial resolution at which source information could be obtained with these global models was limited to the continental scale. Furthermore, the halocarbon lifetimes are not known exactly, and this affects the models' capability to derive emission strengths. In fact, halocarbon lifetimes can be estimated using inverse models with prescribed emissions (Prinn et al., 2000).

Inverse methods have also been used to determine regional-scale halocarbon emission fluxes. For instance, Manning et al. (2003) and O'Doherty et al. (2004) used data from Mace Head, a Lagrangian particle dispersion model
(LPDM), and a so-called simulated annealing technique to estimate halocarbon emissions over Europe. Even simple back trajectories combined with statistical methods have been used to derive halocarbon emission patterns qualitatively (Maione et al., 2008; Reimann et al., 2004, 2008). Over the short time intervals (about 4-10 d) typically covered by back trajectories, halocarbons are almost perfectly conserved. Thus, such methods are little affected by uncertainties in a substance's atmospheric lifetime. However, they can only account for emissions that have occurred during the period of the calculation and leave a large fraction of the measured concentration unexplained. This so-called baseline, often said to be measured in air masses not recently perturbed by emissions, must be subtracted from the measurements before the data can be used for the inversion. Unfortunately, the time scale over which individual recent emission pulses are diluted by mixing with other air masses to an extent that they become part of the baseline is highly variable and depends both on the history of emission input and mixing. Therefore, the baseline is not clearly defined (especially in the Northern Hemisphere where emissions are large), and methods to determine it have all been subjective (see, e.g., Manning et al., 2003; Reimann et al., 2004; Maione et al., 2008). Furthermore, the inversion algorithms used on the regional scale (e.g. Manning et al., 2003; O'Doherty et al., 2004; Maione et al., 2008; Reimann et al., 2004, 2008) have not made use of a priori information (e.g., emissions based on halocarbon production and/or consumption data). In general, using a priori information allows higher resolution in the inversion result, especially when the number of observations is small. From a Bayesian perspective, an inversion using a priori information searches the most likely solution in view of both the a priori emissions and the measured data.

An even simpler method of quantifying emission fluxes uses only measurement data. If the emissions of one chemical species with a lifetime longer than the duration of a typical transport event (e.g., carbon monoxide) are well known and halocarbon emissions are reasonably well correlated with them (ideally with co-located sources), the unknown halocarbon emissions can be determined by the ratio of the measured concentration enhancements of the two species over their baseline (see Dunse et al., 2005; Yokouchi et al., 2006; Millet et al., 2009, for examples). When combined with trajectory calculations, even regional quantification is possible to some extent.

In this paper, we develop a formal inversion method to determine the distribution of HFC and HCFC sources. The advantages of our method are its analytical formulation which facilitates an efficient and accurate inversion, its capability of deriving both regional and global source strengths, the use of a priori information, and an appropriate treatment of uncertainties in the input data. The inversion builds on $20 \mathrm{~d}$ backward simulations with a LPDM, which means that it is not affected by uncertainties in the halocarbon lifetimes. While a baseline must be determined, for the first time this 
Table 1. List of the measurement stations, their coordinates, the networks they belong to, and the period for which data were available.

\begin{tabular}{lccrcc}
\hline Station & Latitude & Longitude & Altitude $(\mathrm{m})$ & Network & Period \\
\hline Mace Head, Ireland & 53.3 & -9.9 & 25 & AGAGE & $1 / 2005-3 / 2007$ \\
Trinidad Head, California & 41.0 & -124.1 & 140 & AGAGE & $1 / 2005-3 / 2007$ \\
Cape Grim, Tasmania & -40.7 & 144.7 & 164 & AGAGE & $1 / 2005-3 / 2007$ \\
Ragged Point, Barbados & 13.2 & -59.4 & 42 & AGAGE & $5 / 2005-3 / 2007$ \\
Cape Matatula, American Samoa & -14.2 & -170.6 & 77 & AGAGE & $5 / 2006-3 / 2007$ \\
Jungfraujoch, Switzerland & 46.5 & 8.0 & 3580 & SOGE & $1 / 2005-3 / 2007$ \\
Monte Cimone, Italy & 44.2 & 10.7 & 2165 & SOGE & $1 / 2005-3 / 2007$ \\
Zeppelin, Spitsbergen & 78.9 & 11.9 & 478 & SOGE & $1 / 2005-12 / 2006$ \\
Hateruma, Japan & 24.0 & 123.8 & 47 & NIES & $1 / 2005-3 / 2007$ \\
\hline
\end{tabular}

is done here in a way that is fully consistent with both the measurements and the model formulation. The uncertainty treatment also allows, for the first time in regional-scale inversions of halocarbon emissions, to use data from several stations concurrently. We apply the method here to HFC and HCFC emissions but it is suitable also for other long-lived trace gases.

We extensively test the new method at the example of the air-conditioning refrigerant HFC-134a because of the large measurement data set available for this substance. The atmospheric abundance of HFC-134a, which has a lifetime of 14 years, is increasing at a rapid rate, in response to its growing emissions arising from its role as a replacement for CFC refrigerants (McCulloch et al., 2003). We then apply the method also to HFC-152a and HCFC-22 whose emissions are also still growing and a matter of concern.

\section{Measurement data}

The HFC and HCFC data used in our inversions come from the three in situ atmospheric measurement networks listed in Table 1: Advanced Global Atmospheric Gases Experiment (AGAGE) (Prinn et al., 2000); System for Observation of Halogenated Greenhouse Gases in Europe (SOGE) (Greally et al., 2007); and Japanese National Institute for Environmental Studies (NIES) (Yokouchi et al., 2006). Each of these networks uses automated low-temperature preconcentration and re-focussing to measure HFCs and HCFCs with an automated gas chromatograph/mass spectrometer (GC/MS). All the modelled data were averaged over 3-hourly intervals and paired with the corresponding 3-hourly model results for the respective measurement station. We use data from January 2005 to March 2007.

At the five AGAGE stations, 21 of ambient air are collected through stainless steel sampling lines and are analysed every two hours for about 40 analytes, including the HFCs and the HCFC modelled here, using a "Medusa" automated preconcentration and GC/MS instrument. The Medusa instrument employs two cryogenic traps to preconcentrate and refocus the 40 analytes from 21 air samples prior to injec- tion into the GC/MS, which is automated with custom control and data acquisition software. The Medusa instrument system, its operation and calibration procedures, and its performance, are described in detail by Miller et al. (2008).

At the SOGE stations Jungfraujoch and Zeppelin, the ADS GC/MS system developed for AGAGE and described by Simmonds et al. (1995) and Reimann et al. $(2004,2008)$ is used. Every four hours, 18 halocarbons are analysed using 21 of air. At the SOGE site of Monte Cimone a similar system as at Jungfraujoch and Zeppelin is in operation (Maione et al., 2004, 2008). Differences are that sampling is performed every three hours with only 11 of air. For all SOGE stations calibration is performed in a similar way as for the Medusa system.

The NIES station at Hateruma uses the analytical system described in detail by Enomoto et al. (2005) and Yokouchi et al. (2006). 11 of ambient air is transferred by a stainless steel tube to the preconcentration system. Samples are analyzed once an hour, and after every five air analyses a gravimetrically prepared standard gas is analyzed for quantification.

Measurements of HFC-134a, HFC-152a and HCFC-22 in the AGAGE and SOGE networks are reported on the SIO2005 primary calibration scale (Prinn et al., 2000; Miller et al., 2008) through a series of comparisons between networks and should be directly comparable. The NIES data are independently calibrated using the Taiyo Nissan gravimetric scale but intercomparisons done for the period January-April 2008 showed excellent agreement with the SIO calibrations, with NIES/AGAGE ratios of 1.005 for HFC-134a, 1.004 for HFC152a, and 0.987 for HCFC-22. For the inversions, we ignore these small differences.

\section{Model calculations}

The inversion procedure is based on backward simulations with the LPDM FLEXPART (Stohl et al., 1998, 2005, see also http://transport.nilu.no/flexpart). FLEXPART was validated with data from continental-scale tracer experiments (Stohl et al., 1998) and has been used in a large number of studies on long-range atmospheric transport (e.g., Stohl et al., 


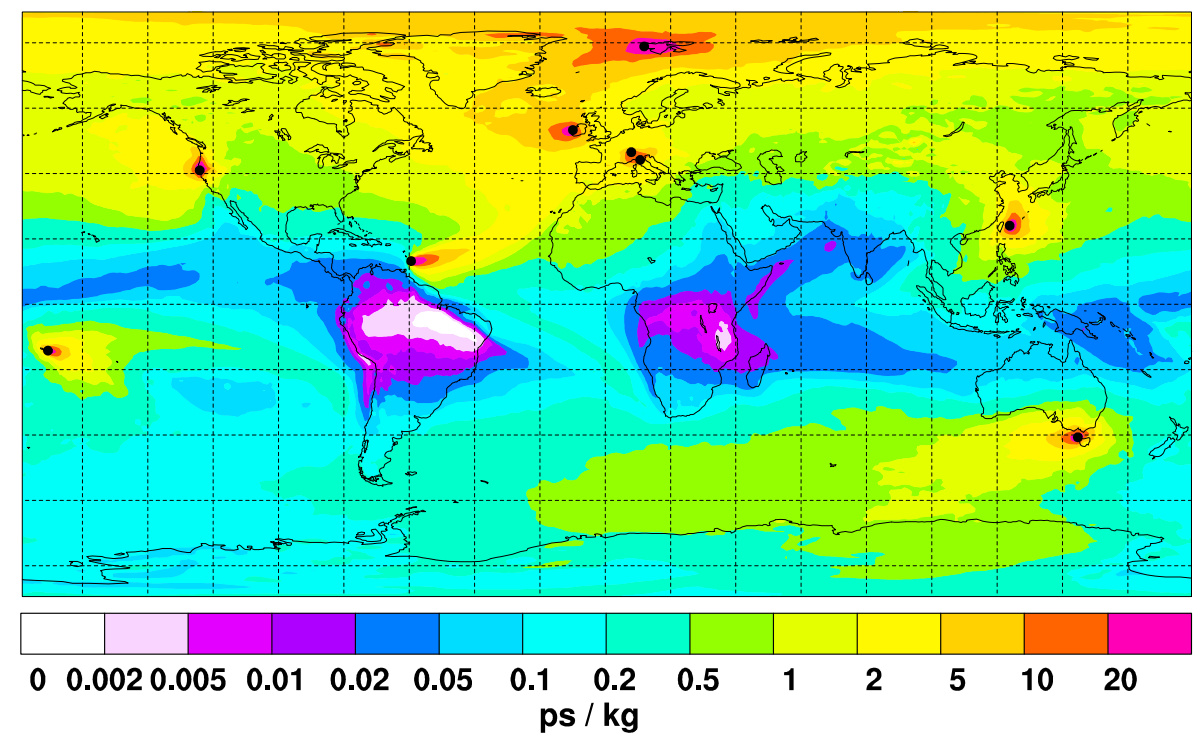

Fig. 1. Footprint emission sensitivity (i.e., SRR) in picoseconds per kilogram obtained from FLEXPART $20 \mathrm{~d}$ backward calculations for the entire network of stations and averaged over the period January 2005 til March 2007. Measurement sites are marked with black dots.

2002, 2003; Damoah et al., 2004; Stohl et al., 2007; Eckhardt et al., 2007). Here it was driven with operational analyses from the European Centre for Medium-Range Weather Forecasts (ECMWF, 2002) with $1^{\circ} \times 1^{\circ}$ resolution. In addition to the analyses at 00:00, 06:00, 12:00 and 18:00 UTC, 3-h forecasts at 03:00, 09:00, 15:00 and 21:00 UTC were used. The ECMWF data had 60 vertical levels until January 2006; 91 vertical levels since then. No model calculations were made for February 2006 because of this discontinuity.

FLEXPART calculates the trajectories of tracer particles using the mean winds interpolated from the analysis fields plus random motions representing turbulence (Stohl and Thomson, 1999). For moist convective transport, FLEXPART uses the scheme of Emanuel and Živković-Rothman (1999), as implemented and tested in FLEXPART by Forster et al. (2007a). A special feature of FLEXPART is the possibility to run it backwards in time (Seibert and Frank, 2004). Such backward simulations from the measurement sites were made every $3 \mathrm{~h}$. During every 3 -h interval, 40000 particles were released at the measurement point and followed backward in time for $20 \mathrm{~d}$ to calculate an emission sensitivity, called source-receptor-relationship (SRR) by Seibert and Frank (2004). The SRR value (in units of $\mathrm{sg}^{-1}$ ) in a particular grid cell is proportional to the particle residence time in that cell and measures the simulated mixing ratio at the receptor that a source of unit strength $\left(1 \mathrm{~kg} \mathrm{~s}^{-1}\right)$ in the cell would produce. The SRR was calculated without considering removal processes. For HFC-152a, the species with the shortest atmospheric lifetime considered in this paper $(567 \mathrm{~d}), 3.5 \%$ would be lost after the maximum transport time of $20 \mathrm{~d}$, which introduces a systematic underprediction of the emissions in the inversion of $<3.5 \%$. For the longer- lived species HFC-134a and HCFC-22, this systematic error would be considerably smaller and, thus, we do not consider it further. Of particular interest is the SRR close to the surface, as most emissions occur near the ground. Thus, we use SRR values for a so-called footprint layer 0-100 $\mathrm{m}$ above ground as the input to the inversion procedure. Folding (i.e., multiplying) the SRR footprint with the emission flux densities (in units of $\mathrm{kg} \mathrm{m}^{-2} \mathrm{~s}^{-1}$ ) (taken from an a priori emission inventory or from the inversion result) yields the geographical distribution of sources contributing to the simulated mixing ratio at the receptor. Spatial integration of these source contributions gives the simulated mixing ratio at the receptor.

Figure 1 shows the emission sensitivity in the footprint layer (i.e., the SRR) obtained from the $20 \mathrm{~d}$ FLEXPART backward calculations for the entire network of stations as an average over the entire period investigated. There is a tendency of the network to sample ocean areas better than land areas on the $20 \mathrm{~d}$ time scale, which hampers the ability of the inversion method to determine emission source strengths over land. While some continents in the Northern Hemisphere (particularly Europe but also North America and large parts of Asia) are still quite well sampled, there are large regions with very low sensitivity over tropical South America and Africa. Also India, Indonesia and northern Australia are not well covered. This means that emissions in these areas cannot be well determined.

The choice of the $20 \mathrm{~d}$ length of the backward simulations was motivated by the fact that the value for the inversion of every additional simulation day decreases rapidly with time backward. This has three reasons: 1) Since we were using data from surface stations, the total emission sensitivity in the footprint layer per day of backward calculation is largest 
shortly before the arrival of air at the receptor. Before, particles may have resided above the boundary layer, in which case they do not contribute to the emission sensitivity. 2) Due to turbulent mixing and convection, the volume (or area) over which emission sensitivities are distributed grows with time. This makes it more and more difficult with time to extract information on individual emission sources (this is a consequence of the second law of thermodynamics). In other words, with time the emission contributions from various regions become more and more well mixed and start forming the baseline. 3) Model errors also grow with time. On the other hand, the computational cost of the model calculations per day of simulation even increases slightly with time because the convection scheme must be called for a growing number of grid columns. All this suggests a relatively early termination of the backward calculation. Model experiments show that for most stations a duration of about $5 \mathrm{~d}$ is sufficient to explain most of the concentration variability. The extra $15 \mathrm{~d}$ add relatively little to the concentration variability and, thus, longer simulations than $20 \mathrm{~d}$ would not result in a better reconstruction of emission sources. Notice, however, that the baseline as defined below depends on the duration of the simulation: longer simulations result in a lower baseline, as more emissions are directly accounted for.

\section{Inversion method}

\subsection{General theory}

The estimation of gridded HFC emissions is based on the analytic inversion method of Seibert $(2000,2001)$. This method has recently been expanded by Eckhardt et al. (2008) to estimate the vertical distribution of sulfur dioxide emissions in a volcanic eruption column. They improved it to allow for an a priori for the unknown sources, a Bayesian formulation considering uncertainties for the a priori and the observations and an iterative algorithm for ensuring a solution with only positive values. Here, the method is extended further considering a baseline in the observations which is adjusted as part of the inversion process, and more detailed quantification of errors. We repeat here the mathematical framework of the inversion, modified to include these extensions and adapted to other peculiarities of the problem. For a more detailed discussion of chemical data assimilation and inverse modelling, see Kasibhatla (2000) and Enting (2002).

We want to retrieve $n$ unknowns which are put into a vector $\boldsymbol{x}$, while the $m$ observed values are put into a vector $\boldsymbol{y}^{\boldsymbol{o}}$, where the superscript $o$ stands for observations. Modeled values $\boldsymbol{y}$ corresponding to the observations can be calculated as

$$
\boldsymbol{y}=\boldsymbol{M x}
$$

implying a linear relationship. The $m \times n$ matrix $\boldsymbol{M}$ contains the sensitivities of the modelled values $\boldsymbol{y}$ with respect to the unknowns $\boldsymbol{x}$. The unknowns include the gridded emission values as well as free parameters in the description of the baseline. The sensitivity with respect to emissions is obtained from $m$ FLEXPART backward simulations, each with a transport time of $20 \mathrm{~d}$. The transport model thus represents only concentration fluctuations caused by emissions during this time window of the air mass history. Older emissions produce a background or baseline mixing ratio in the observations to which the explicitly modelled part is added. As the emission sensitivity for an age of $>20 \mathrm{~d}$ is spread over large areas of the globe, the respective mixing ratio contributions at a station vary rather smoothly with time. Therefore we describe the baseline as a continuous, stepwise linear function with $n_{2}$ segments of $31 \mathrm{~d}$ length. The values at the $n_{2}$ nodes together with the $n_{1}$ emission values are the $n=n_{1}+n_{2}$ unknowns. More details are given later.

Typically, observations do not contain sufficient information to constrain well all elements of the source vector, making the problem ill-conditioned. Therefore, regularization or, in other words, additional information is necessary to obtain a meaningful solution. Often this additional information is provided in the form of a priori estimates of the unknowns. In combination with a quantification of the uncertainties of both unknowns and observations this leads to a Bayesian inversion minimizing a corresponding cost function.

If there is an a priori source vector $\boldsymbol{x}^{a}$, we can write

$$
\boldsymbol{M}\left(\boldsymbol{x}-\boldsymbol{x}^{a}\right) \approx \boldsymbol{y}^{o}-\boldsymbol{M} \boldsymbol{x}^{a}
$$

and as an abbreviation

$$
M \tilde{\boldsymbol{x}} \approx \tilde{\boldsymbol{y}}
$$

Considering only the diagonals of the error covariance matrices (i.e., only standard deviations of the errors while assuming them to be uncorrelated), the cost function to be minimized is

$$
\begin{aligned}
& J=(M \tilde{\boldsymbol{x}}-\tilde{\boldsymbol{y}})^{T} \operatorname{diag}\left(\sigma_{o}{ }^{-2}\right)(M \tilde{\boldsymbol{x}}-\tilde{\boldsymbol{y}})+ \\
& \tilde{\boldsymbol{x}}^{T} \operatorname{diag}\left(\sigma_{\boldsymbol{x}}{ }^{-2}\right) \tilde{\boldsymbol{x}}
\end{aligned}
$$

The first term on the right hand side of Eq. 4 measures the misfit model-observation, and the second term measures the deviation from the a priori values. $\sigma_{o}$ is the vector of standard errors of the observations, and $\sigma_{x}$ the vector of standard errors of the a priori values. The operator $\operatorname{diag}(\boldsymbol{a})$ yields a diagonal matrix with the elements of $\boldsymbol{a}$ in the diagonal.

The above formulation implies normally distributed, uncorrelated errors, a condition that we know to be not fulfilled. Observation errors (also model errors are subsumed in this term) may be correlated with neighboring values, and deviations from the a priori sources are asymmetric. The justification for using this approach is the usual one: the problem becomes much easier to solve, detailed error statistics are unknown anyway, and experience shows that reasonable 
results can be obtained. The implications of assuming normally distributed errors and how this limitation can be partly overcome follow later.

Minimization of $J$ leads to a linear system of equations (LSE) to be solved for $\tilde{\boldsymbol{x}}$ (Menke, 1984):

$$
\begin{aligned}
& {\left[M^{T} \operatorname{diag}\left(\sigma_{o}{ }^{-2}\right)\right] M+\operatorname{diag}\left(\sigma_{x}{ }^{-2}\right) \tilde{x}=} \\
& M^{T} \operatorname{diag}\left(\sigma_{o}{ }^{-2}\right) \tilde{y}
\end{aligned}
$$

The LSE is solved with the LAPACK ${ }^{1}$ driver routine SGESVX, based on $L U$ factorisation with calibration of rows and columns (if necessary) and iterative refinement of the solution.

Our algorithm presently does not yield an estimate of the uncertainty of $\boldsymbol{x}$. This desirable feature will be the subject of future development. However, already in its present development state, our algorithm is a substantial improvement over existing methods to determine regional halocarbon emission fluxes (e.g., Manning et al., 2003; Reimann et al., 2008), which do not consider uncertainties at all, also not in the input data.

\subsection{Positive definiteness}

Small negative "emissions" are not unrealistic in regions remote from industrial sources given that chemical and ocean sinks exist for halocarbons. These negative "emissions" are, however, relatively homogeneously distributed over the globe and of a small magnitude compared to the localized emission fluxes. Therefore, the halocarbon sinks will not cause major episodic behavior in the data and, thus, will mainly affect the baseline level. However, inaccuracies in model and data will in general cause our method to find solutions containing unrealistic negative emissions that are larger than expected. In the linear framework this cannot be prevented directly as positive definiteness is a nonlinear constraint. A workaround that has been adopted by Eckhardt et al. (2007) and which is also used here is to repeat the inversion after reducing the standard error values for those source vector elements that are negative, thus binding the solution closer to the non-negative a priori values. This procedure is iterated until the sum of all negative emissions is less than $3 \%$ of the sum of the positive emissions. The standard errors are correspondingly recalculated in each step as

$$
\sigma_{x j}^{i}= \begin{cases}0.5 \sigma_{x j}^{i-1} & \text { if } \quad x_{j}^{i-1}<0 \\ \operatorname{Min}\left(1.2 \sigma_{x j}^{i-1}, \sigma_{x j}^{1}\right) & \text { if } \quad x_{j}^{i-1} \geq 0\end{cases}
$$

where $x_{j}^{i-1}$ and $\sigma_{x j}^{i}$ denote the $j$-th elements of the source vector and of the vector of uncertainties in the a priori source values, respectively, for the $i$-th iteration step.

\footnotetext{
${ }^{1}$ LAPACK is a free linear algebra package available from http:// www.netlib.org/lapack/, also included with commercial FORTRAN and $\mathrm{C}$ compilers.
}

\subsection{The baseline definition}

The substances studied here have lifetimes of the order of years. They are relatively well mixed in the troposphere and have a baseline upon which concentration variations are superimposed as a result of episodic transport events. The FLEXPART $20 \mathrm{~d}$ backward simulations capture the concentration variations due to the episodic transport but not the baseline. The concentration variations contain most of the information about the regional emission distribution but the baseline must be added to the model results in order to use the inversion method. The baseline varies geographically and changes over time as the emission fluxes are not in equilibrium with the loss processes. In previous studies, various subjective combinations of data analysis and modeling were used to determine the baseline for individual stations (Manning et al., 2003; Greally et al., 2007). We aimed at a more objective method that can be applied equally for all stations and that is consistent with our modeling approach. Thus, we define the baseline as that part of the measured concentration averaged over $31 \mathrm{~d}$ that cannot be explained by emissions occurring on the $20 \mathrm{~d}$ time scale of the model calculations. Notice that the $31 \mathrm{~d}$ averaging interval is a compromise between the desired capacity to describe temporal variations of the baseline and the need to limit the number of unknowns in the inversion. Notice also that this interval is not in any way related to the $20 \mathrm{~d}$ duration of the backward calculations.

Modelled concentrations are split into a part described by the transport simulation $y_{1 l}$ and the baseline part $y_{2 l}$ :

$$
y_{l}=y_{1 l}+y_{2 l}=y_{1 l}+y_{k}^{b}+\frac{t_{l}-t_{k}}{t_{k+1}-t_{k}}\left(y_{k+1}^{b}-y_{k}^{b}\right)
$$

where $l$ denotes a specific observation, $k=1, \ldots, n_{2}$ is the number of the corresponding node and $y_{k}^{b}$ is the baseline value at node $k$ (these values can be identified as the baseline-related part of the vector of unknowns, $\boldsymbol{x}_{2}$ ). For an element $l$ of the modelled time series, referring to a time $t_{l}, k$ refers to the node of the corresponding station and the point in time where $t_{k} \leq t_{l}<t_{k+1}$.

The derivation of the sensitivies

$$
m_{k l}=\frac{\partial y_{2 l}}{\partial x_{k}}=\frac{\partial y_{2 l}}{\partial y_{k}^{b}}
$$

from Eq. 7 is trivial and corresponds to a linear interpolation between baseline values at nodes $k$ and $k+1$.

\subsection{A priori baseline parameters and their uncertainty}

For the practical application, $\boldsymbol{x}^{\boldsymbol{a}}, \boldsymbol{\sigma}_{\boldsymbol{x}}$ and $\sigma_{\boldsymbol{o}}$ need to be assigned proper values. Regarding the a priori baseline values (part of $\boldsymbol{x}^{\boldsymbol{a}}$ ), they could simply be taken as the average measured mixing ratio minus the average a priori simulated mixing ratio during a $31 \mathrm{~d}$ interval. However, in order to reduce the dependence of the baseline on the a priori emissions, we 
filter out pollution events by excluding data above the median of both the measured and the simulated values. Notice that for a polluted site with frequent contributions from recent emissions, the baseline defined in that way can be below the lowest measured value, in contrast to previous methods (Manning et al., 2003; Greally et al., 2007). The uncertainty of the baseline values is taken to be $40 \%$ of the average a priori simulated emission contribution from the past $20 \mathrm{~d}$, consistent with the assumed uncertainty for the emissions (see Sect. 4.5).

\subsection{A priori emission data and their uncertainty}

Regarding the a priori HFC-134a emissions (part of $\boldsymbol{x}^{\boldsymbol{a}}$ ), we took projections of global total emissions from Ashford et al. (2004b) for the years from 2005-2007 and slightly adjusted them to make them fit with the AFEAS (2007) values for the year 2005-the last year available with non-forecast data. When an inversion is done for a multi-year period, an average value weighted with the number of observations available for the individual years is taken and the emissions are assumed to be constant.

For the spatial distribution of the emissions, we used total emissions for the year 2005 for countries where such information was available through the United Nations Framework Convention on Climate Change (UNFCCC, see http: //unfccc.int). The country totals were disaggregated within each country's borders according to a gridded population density data set (CIESIN, 2005). We then subtracted the total UNFCCC emission from the global total AFEAS emission and attributed the remaining emissions to all countries not covered in the UNFCCC database, again distributing the emissions according to the CIESIN population. We also tested alternative disaggregation methods (see Sect. 5.2).

Emission inventories tell us that HFC and HCFC emissions occur basically only over land. Therefore, grid cells covered entirely by ocean are assumed to have zero emissions and are consequently not included in the source vector, except for one sensitivity test.

The uncertainties of the emissions, $\sigma_{x}$, need to be specified for every grid cell. Unfortunately, no information on these uncertainties is actually available. Therefore, we have used $\sigma_{x j}=\max \left(0.4 x_{j}^{a}, \overline{x^{a}}\right)$, where $\overline{x^{a}}$ is the global average emission flux over the continents. The magnitude of these uncertainties was determined by trial and error, and was chosen to allow substantial corrections to the initial emission distribution.

\subsection{Observation-related uncertainties}

The vector $\sigma_{\boldsymbol{o}}$ should describe the part of the misfit between the observations and the model results which is not due to wrong emissions. Thus it contains the measurement error as well as model errors. While information on measurement errors can be assessed from instrument characteristics, inter- comparison tests etc., information on model errors is difficult to obtain, though we assume that it is the dominant contribution. Our first approach was to specify a $\sigma_{o}$ for each individual station, as their characteristics are quite different, but to assume it to be constant in time. It would be determined as the root mean square (RMS) error between a priori model output and observation, averaged for each station. Note that this is likely to be an overestimation.

Investigating the resulting error statistics, both for the a priori and a posteriori results, we found that they are not normally distributed. This is mainly caused by a higher frequency of extreme values than expected for a normal distribution (i.e., a positive kurtosis excess), whereas the central part of the distribution is very close to normal (Fig. 2).

Another interesting feature is the amount of error reduction that is achieved in the inversion (Table 2). We see that for the two mountain stations, Jungfraujoch and Monte Cimone, the errors are much larger both before and after the inversion than for other stations. This is quite understandable as in mountain areas, processes that are relevant for transport cannot be resolved well, or not at all, by a global meteorological model such as used at ECMWF (see Seibert and Skomoroski, 2008). For instance, a mountain station can be influenced by up-slope flows bringing polluted air from a valley, which cannot be represented correctly by the model. Such kind of transport events would be associated with underprediction by the model, and indeed as seen in Fig. 2 only the left tail is heavy at Jungfraujoch. These errors are "incurable" - the inversion cannot improve the agreement between the observations and the model results substantially. However, as the inversion minimizes quadratic errors, without additional measures taken they could have a disproportionately large influence on the inversion result. As the theoretical approach implies normally distributed errors, the solution obtained is no more the most likely one in a Bayesian sense.

We tried to overcome this problem by assigning larger $\sigma_{o}$ values to observations causing very large errors. The kurtosis $K$ of the error frequency distribution is used to identify such large errors. For most stations, $K$ is big if all errors are included. Therefore, we sorted out the largest absolute errors step by step until $K$ of the remaining error values is below 5 . The errors sorted out in this procedure were not entirely removed from the inversion but their corresponding $\sigma_{o k}$ were increased such that the frequency distribution of $e_{k} / \sigma_{o k}$ (where $e_{k}$ are the individual errors) fits a normal distribution with a standard deviation taken from the central part of the error distribution. The standard errors are first calculated using the a priori model results and are then re-calculated in three iteration steps using the a posteriori model results. The standard errors change only a little after the first iteration. Figure 2 shows the effect of this normalization. At Mace Head, the a priori error distribution is roughly Gaussian between values of -1 and +1.5 of the normal order statistic medians and this range is somewhat extended by the inversion. However, there is a quite heavy tail on both ends. 
Table 2. Error reduction for HFC-134a achieved in the inversion by station. $E^{a}$ and $E^{b}$ denote the a priori and, respectively, a posteriori RMS errors where, however, those observations on the tail which were assigned an increased $\sigma_{o k}$ are not included. $y^{o}$ are the mean observed concentrations, which are however not fully comparable due to different gaps in the time series. $1-E^{b} / E^{a}$ is the relative error reduction. $E_{n}^{b}$ is the a posteriori error normalized with the standard deviation of the observed concentrations minus the baseline, again with clipped tails. $N$ denotes the number of observations considered, whereas $n / N_{t}$ is the percentage of observations skipped. $r_{b l}^{2}$ is the squared Pearson correlation coefficient between the observations and the a priori baseline. $r_{e a}^{2}$ and $r_{e b}^{2}$ are the squared Pearson correlation coefficients between the observations minus the a priori and, respectively, a posteriori baseline, and the modeled a priori and, respectively, a posteriori $20 \mathrm{~d}$ source contributions. $r_{a}^{2}$ and $r_{b}^{2}$ are the squared Pearson correlation coefficients between the observations and the total a priori and, respectively, a posteriori model results. Stations are ordered with ascending a posteriori RMS errors $\left(E^{b}\right)$.

\begin{tabular}{lrrrrrrrrrrrr}
\hline Station & $\begin{array}{r}y^{o} \\
\text { pptv }\end{array}$ & $\begin{array}{r}E^{a} \\
\text { pptv }\end{array}$ & $\begin{array}{r}E^{b} \\
\text { pptv }\end{array}$ & $1-E^{b} / E^{a}$ & $E_{n}^{b}$ & $N$ & $n / N_{t}$ & $r_{b l}^{2}$ & $r_{e a}^{2}$ & $r_{e b}^{2}$ & $r_{a}^{2}$ & $r_{b}^{2}$ \\
\hline Cape Grim & 33.5 & 0.61 & 0.35 & $41.9 \%$ & $64 \%$ & 4802 & $2.14 \%$ & 0.87 & 0.23 & 0.40 & 0.89 & 0.92 \\
Zeppelin & 42.4 & 0.68 & 0.56 & $17.1 \%$ & $80 \%$ & 2223 & $0.09 \%$ & 0.94 & 0.31 & 0.40 & 0.93 & 0.95 \\
Samoa & 38.0 & 0.86 & 0.86 & $0.1 \%$ & $99 \%$ & 1616 & $0.00 \%$ & 0.78 & 0.04 & 0.03 & 0.79 & 0.78 \\
Mace Head & 43.3 & 1.80 & 1.09 & $39.8 \%$ & $37 \%$ & 4585 & $2.01 \%$ & 0.44 & 0.55 & 0.74 & 0.75 & 0.86 \\
Barbados & 40.7 & 1.55 & 1.35 & $12.5 \%$ & $95 \%$ & 3424 & $0.03 \%$ & 0.67 & 0.03 & 0.11 & 0.68 & 0.74 \\
Trinidad Head & 43.2 & 3.01 & 1.36 & $54.8 \%$ & $86 \%$ & 4243 & $0.56 \%$ & 0.68 & 0.11 & 0.22 & 0.50 & 0.77 \\
Hateruma & 40.3 & 1.83 & 1.39 & $23.9 \%$ & $71 \%$ & 5460 & $0.24 \%$ & 0.73 & 0.22 & 0.42 & 0.78 & 0.85 \\
Jungfraujoch & 45.8 & 4.19 & 4.00 & $4.6 \%$ & $90 \%$ & 3309 & $1.87 \%$ & 0.03 & 0.03 & 0.04 & 0.08 & 0.11 \\
Monte Cimone & 51.2 & 7.89 & 7.13 & $9.6 \%$ & $91 \%$ & 2444 & $0.29 \%$ & 0.23 & 0.09 & 0.16 & 0.30 & 0.39 \\
\hline
\end{tabular}

Our variable observation error standard deviations are able to bring these tails quite close to the normal distribution after the inversion. At Jungfraujoch, we notice that positive errors (overprediction) have a thin tail both before and after the inversion while the negative tail, indicating underprediction, is extremely heavy. Also here the variable weights bring the left tail of the distribution much closer to normal.

The column with the normalized a posteriori errors $\left(E_{n}^{b}\right)$ in Table 2 is the best available information on the performance of the model for each station, but we need to consider that the worst errors have been excluded from the evaluation. Then, the mountain stations are not standing out anymore - an indication of the high observed variability there. By far the best performance is achieved at Mace Head with a relative error of 0.37. Cape Grim and Hateruma are the next best stations while the others have errors that are not much smaller than the observed variability.

\subsection{Variable-resolution grid for the inversion}

The size of the inversion problem is defined by the number of grid cells for which emission fluxes shall be determined. With a high-resolution global grid the problem becomes quite big (e.g., $1^{\circ} \times 1^{\circ}$ corresponds to 64800 unknowns). To reduce the number of unknowns, we use a variable-resolution grid with high resolution where such high resolution is warranted and lower resolution elsewhere. SRR values are high in the vicinity of the observation sites but they decrease with distance from these sites (Fig. 1) lower resolution is sufficient in these remote areas.

For setting up the variable-resolution grid, we start with a coarse $36^{\circ} \times 36^{\circ}$ global grid, whose resolution is enhanced in four steps to $12^{\circ}, 4^{\circ}, 2^{\circ}$ and $1^{\circ}$, respectively. In every step, grid cells with a large total source contribution (the SRR field shown in Fig. 1 multiplied with the emission flux field) are subdivided, while grid cells with a low source contribution are kept at the coarse resolution. The fraction of boxes subdivided in an iteration step, here set to $50 \%$, determines the total number of grid boxes used for the inversion. This creates a variable-resolution grid that has the highest resolution (up to $1^{\circ}$ ) in high-emission areas around the receptor sites, and the lowest resolution (down to $36^{\circ}$ ) in remote areas with low emission fluxes. An undesirable result of this procedure is that coarse grid cells would be used wherever the a priori emission fluxes are very low, even in areas with large SRR values. To avoid this, a minimum emission flux $(10 \%$ of the global mean) is used for calculating the source contribution values, thus enabling high resolution around the measurement stations even in areas where the a priori emissions are low.

\section{Sensitivity studies}

\subsection{Idealized experiments}

We tested our inversion method by determining the HFC134a emissions in an idealized set-up. For eight stations (Hateruma was removed to make Asia a region with poor data constraints) we fed the FLEXPART a priori model results plus baseline as pseudo measurements into the inversion algorithm. In a first experiment, we used these data directly, in a second one we used them with superimposed noise. We then removed the a priori information by setting 

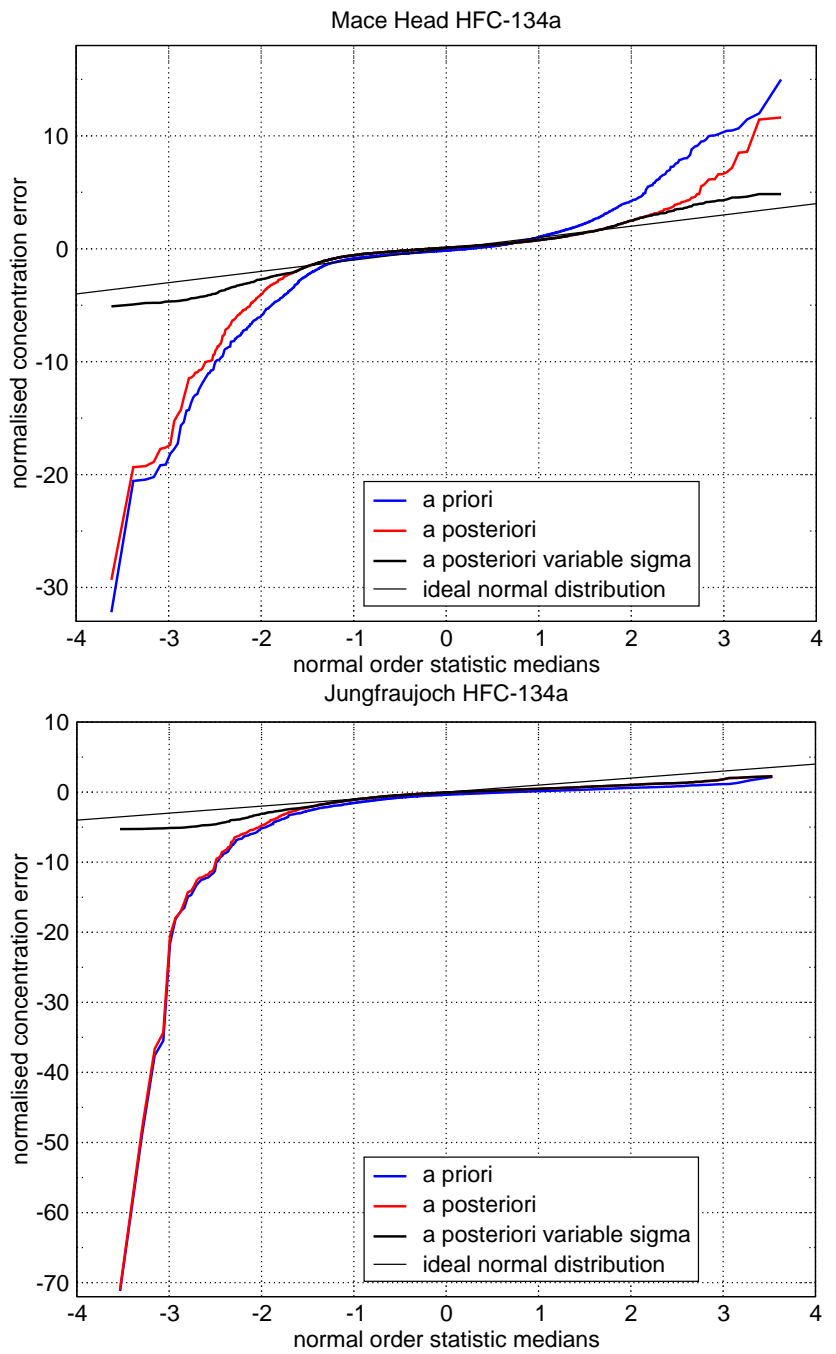

Fig. 2. Normal probability plots of the model errors for HFC-134a inversions at Mace Head (top) and Jungfraujoch (bottom). The abscissa is a function of the percentile values; e.g., about $68 \%$ of the data are found betwen -1 and 1 , about $96 \%$ between -2 and 2 . The ordinate values are error values normalized with the corresponding $\sigma_{o}$, whereas in the curve labelled "a posteriori variable sigma" the normalization is done with a larger $\sigma$ for the tails of the distribution as explained in the text. A normal distribution with $\sigma=1$ is the $1: 1$ line in this plot and added for comparison.

the emissions to zero everywhere. The number of pseudo observations available was 27000 , the number of emission boxes 2800 .

In the experiment without superimposed noise, the AFEAS/UNFCCC/CIESIN (AUC) emission field (Fig. 3a) is almost perfectly reconstructed by the inversion (Fig. 3b), with small differences occurring mostly in Asia where there is a poor constraint by the measurements. Consequently, the a posteriori modeled mixing ratios are virtually identical to the pseudo measurements, as shown for Mace Head (Fig. 4a), which features a Pearson correlation coefficient greater than 0.999. This shows that the inversion algorithm has been set up correctly. However, this experiment is not very realistic as the pseudo measurement data were constructed with the same transport model as was used for the inversion.

In the second experiment we mimicked measurement and model errors by superimposing onto the pseudo measurements normally distributed random noise with stationspecific standard deviation $\sigma_{\boldsymbol{o}}$ (column $E^{b}$ in Table 2). Even for this case, the emission distribution in Europe - the continent best constrained by the measurement data (see Fig. 1) - is very well reconstructed (Fig. 3c) and the total European emission is only overestimated by $8 \%$. Emissions in North America, still reasonably well constrained by the measurements, are also fairly well reproduced with a total overestimate of $17 \%$. However, the emissions in Asia are not well determined, with clearly deficient emission patterns and an overall underestimate of $50 \%$ (a result of the regularization constraining the emissions towards zero). A few "ghost" sources appear at high northern latitudes, and emissions in the Southern Hemisphere (not shown), especially in Africa, are also not well reconstructed: continental totals are in error by more than a factor of 2 . The pseudo measurements at the stations are well reproduced by the inverse model, for instance at Mace Head (Fig. 4b), proving that it is the sparse density of measurement sites outside Europe that is most problematic for the inversion. Another experiment showed that when pseudo measurements for the Hateruma station are added, the emission distribution in eastern Asia is well reconstructed.

5.2 Sensitivity to the a priori emissions and their uncertainties

Next we evaluated the influence of the a priori emission information on the inversion for HFC-134a. All measurements from all stations (32400 values in total) were used, and we studied the following five scenarios:

1. In our standard method, the CIESIN (2005) population map was used for distributing the UNFCCC country emissions as well as the remaining AFEAS emissions without country-specific information (AFEAS/UNFCCC/CIESIN or AUC).

2. The AFEAS global emissions were distributed only according to population without using UNFCCC information (AFEAS/CIESIN or AC).

3. The EDGAR version 3.3 inventory for the year 1995 (Olivier et al., 2001) was used for emission disaggregation (AFEAS/EDGAR or AE).

4. A zero emission flux was assumed everywhere (Zero). 
a) A priori AFEAS/UNFCCC/CIESIN emissions

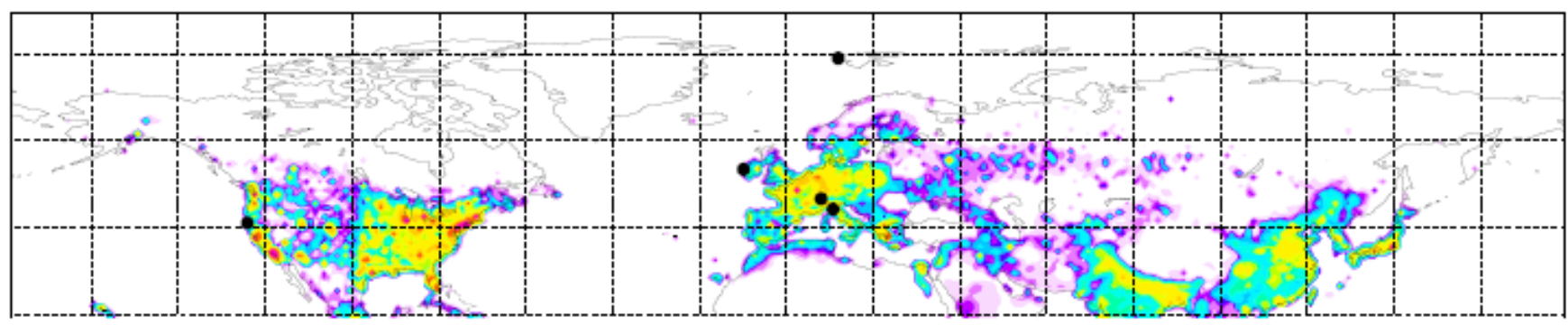

b) A posteriori without noise

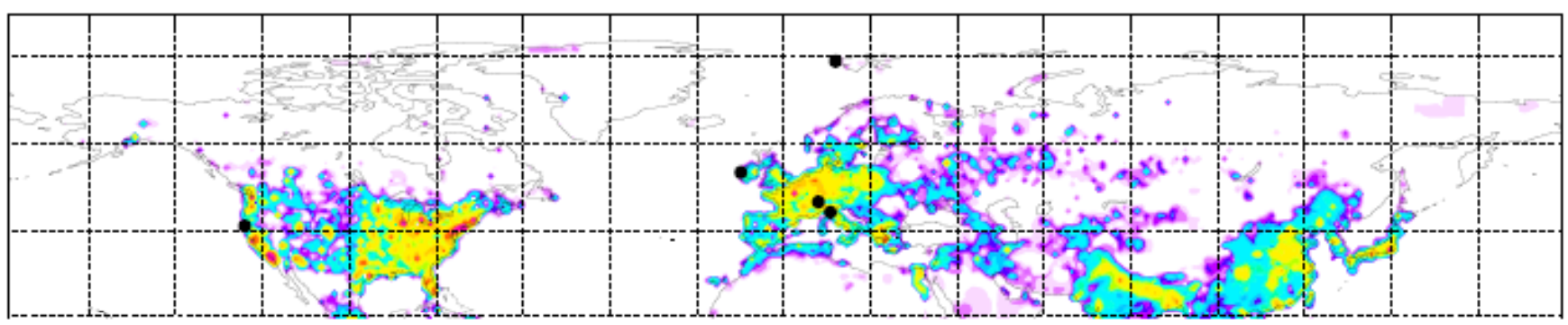

c) A posteriori with noise
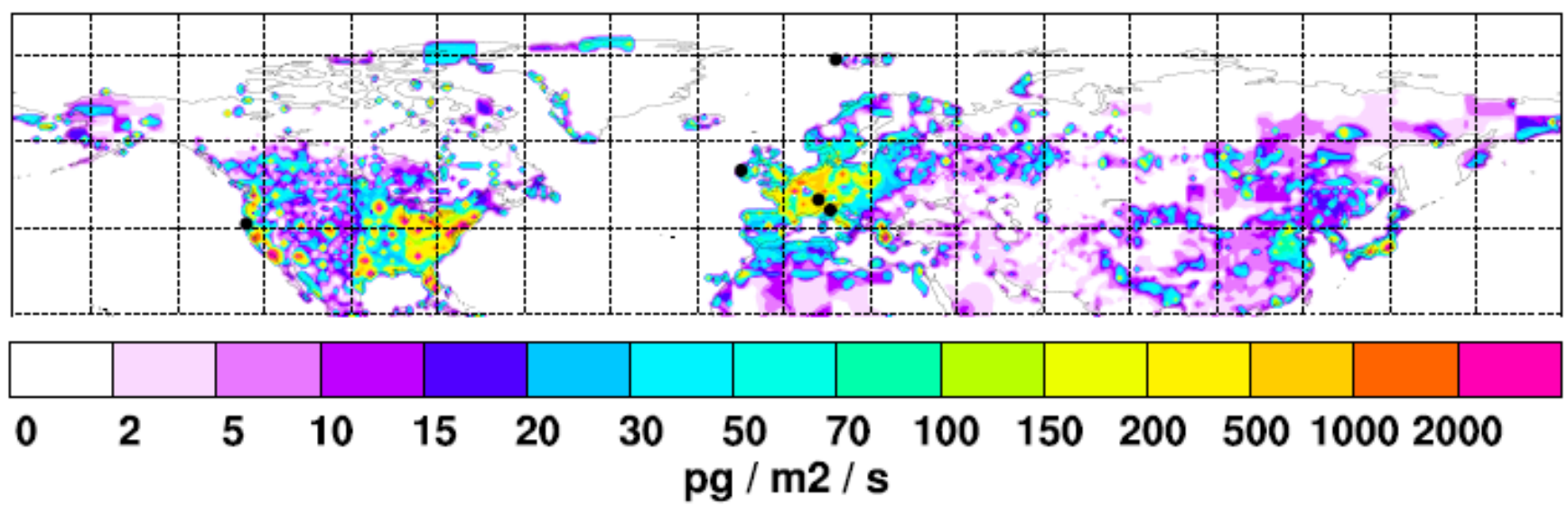

Fig. 3. Distribution of HFC-134a emissions taken from the a priori inventory based on AFEAS, UNFCCC and CIESIN data (a), reconstructed by inversion using the a priori model results as pseudo measurements (b), and reconstructed by inversion using the a priori model results with superimposed noise as pseudo measurements (c). Measurement sites are marked with black dots.

5. Using the AUC a priori, we allowed the inversion to also produce non-zero emission fluxes over the oceans (Ocean).

For the zero emission flux and the AUC inversion we also tested the influence of the assumed emission uncertainty. For that, we replaced our standard scenario (see Sect. 4.5) with a globally constant uncertainty of $200 \%$ of the global mean emission flux.

The three a priori emission distributions (Fig. 5a, b; AC distribution not shown) are quite different from each other. Continental total emissions as reported in Table 3 are a factor of 7 and 6 higher in Africa and Asia for the AC distribution than for the $\mathrm{AE}$ distribution. The $\mathrm{AC}$ distribution does not reflect different degrees of industrialization and likely overestimates emissions in less developed countries. Conversely, emissions in Europe are highest for the AE distribution, a result of the rather outdated EDGAR inventory for the year 1995 when HFC-134a emissions were still heavily weighted towards North America and Europe. The AUC distribution (Fig. 5a) lies between the $\mathrm{AE}$ and $\mathrm{AC}$ distributions (Table 3) and is probably most realistic.

The a posteriori HFC-134a emissions (Fig. 5c, d, Table 3) differ much less than the corresponding a priori emissions. Asian total emissions are more than doubled in the AE case, increased by $12 \%$ in the AUC case, and reduced by $35 \%$ in 
Table 3. Regional HFC-134a emissions (kt/yr) for different spatial disaggregation of the a priori emissions and different assumptions on the emission uncertainty.

\begin{tabular}{|c|c|c|c|c|c|c|c|c|c|c|c|c|c|c|}
\hline \multirow[t]{2}{*}{ Scenario } & \multicolumn{2}{|c|}{ North America } & \multicolumn{2}{|c|}{ Europe } & \multicolumn{2}{|c|}{ Asia } & \multicolumn{2}{|c|}{ South America } & \multicolumn{2}{|c|}{ Africa } & \multicolumn{2}{|c|}{ Australia } & \multicolumn{2}{|c|}{ Total } \\
\hline & prior & posterior & prior & posterior & prior & posterior & prior & posterior & prior & posterior & prior & posterior & prior & posterior \\
\hline AUC & 65 & 43 & 24 & 26 & 41 & 46 & 4 & 22 & 8 & 6 & 2 & 7 & 145 & 156 \\
\hline $\mathrm{AC}$ & 12 & 30 & 14 & 24 & 88 & 57 & 10 & 25 & 15 & 6 & 1 & 5 & 145 & 157 \\
\hline $\mathrm{AE}$ & 49 & 40 & 73 & 32 & 15 & 36 & 3 & 21 & 2 & 9 & 2 & 7 & 145 & 149 \\
\hline Zero & 0 & 20 & 0 & 18 & 0 & 12 & 0 & 7 & 0 & 2 & 0 & 5 & 0 & 64 \\
\hline Zero, invariable & 0 & 17 & 0 & 19 & 0 & 13 & 0 & 11 & 0 & 3 & 0 & 5 & 0 & 70 \\
\hline AUC, invariable & 65 & 52 & 24 & 28 & 41 & 51 & 4 & 28 & 8 & 10 & 2 & 8 & 145 & 184 \\
\hline Ocean & 65 & 38 & 24 & 26 & 41 & 40 & 4 & 11 & 8 & 6 & 2 & 6 & 145 & 141 \\
\hline
\end{tabular}

a) Without noise

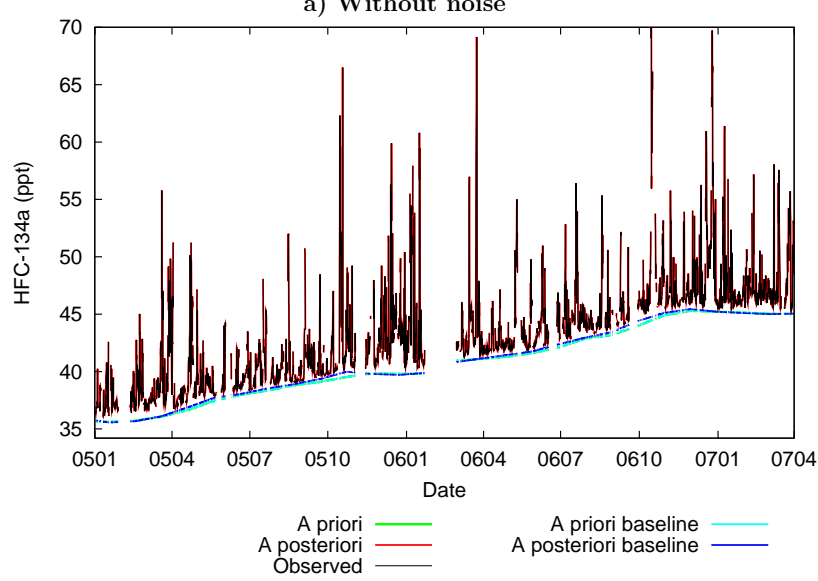

b) With noise

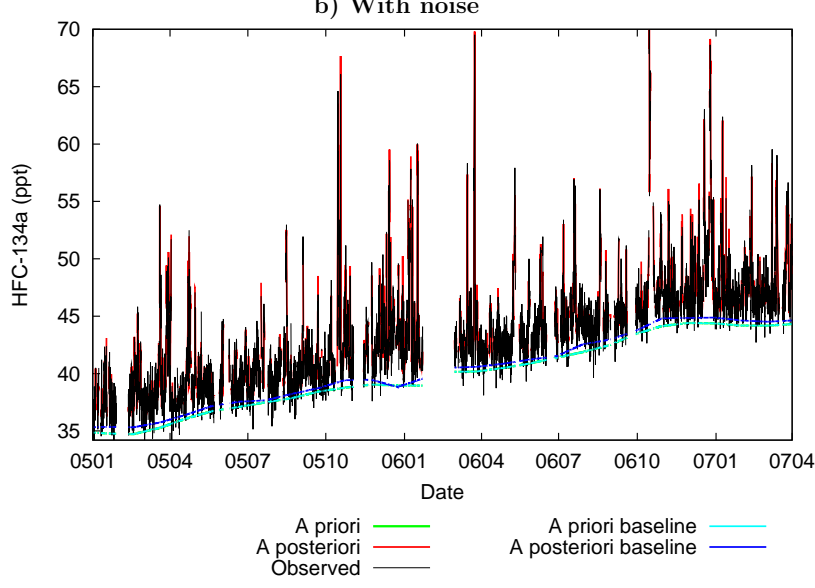

Fig. 4. Time series of HFC-134a at Mace Head from the idealized experiment (a) without noise and (b) with noise superimposed on the pseudo measurement time series. Shown are the a priori (green line) and a posteriori (red line) results, the a priori (cyan line) and a posteriori (blue line) baseline, as well as the pseudo measurements (black line). Notice that the a priori baseline and the total a priori concentrations are identical in this case.

the $\mathrm{AC}$ case, resulting in a maximum difference of $58 \%$ in the total a posteriori emissions, despite the factor 6 difference in the a priori emissions. Emissions in China and Southeast Asia, in particular, are increased substantially in the AE case.
Four stations located in Europe provide a strong constraint on European emissions. The a posteriori total European emissions differ by a maximum of 33\% (24-32 kt/yr, see Table 3), although the AUC, AC and AE a priori emissions differ by more than a factor of 5 . Also the resulting emission distributions within Europe are quite similar. The weaker measurement constraint for North America results in slightly larger differences between the a posteriori total emissions for that continent $(43 \%$ difference compared to more than a factor 5 in the a priori). Australian emissions, constrained mostly by the single station in Cape Grim, Tasmania are increased by approximately a factor of 4 over the a priori estimates. Possible reasons for this large discrepancy in the Southern Hemisphere are discussed below.

The emission changes (a posteriori minus a priori) made by the inversion for the AUC case are shown in Fig. 6a. Large emission reductions occur throughout most of the United States of America (USA), while increases occur in Canada and Alaska. Emission changes in Europe are spatially more complex, with a tendency of emission reductions in Central Europe and emission increases over the United Kingdom, Italy and Spain. In Asia, emissions are reduced by the inversion in India and Southeast Asia but increased over China and Russia.

The zero a priori emissions scenario is particularly revealing, as it shows the capability of the method to identify emission areas without a priori information. Not surprisingly, the a posteriori emissions for this inversion are lower everywhere than when using non-zero a priori emissions (Table 3). However, the emission distribution in Europe is very well represented and total European emissions are only 30\% lower than with the AUC a priori distribution. Quite remarkably, also the strong emissions at the east coast of the USA are well reproduced, even though the constraint on these emissions mostly comes from the European stations (as indicated in Fig. 1 and confirmed by plotting emission sensitivity fields for individual stations (not shown)). Australian emissions are also relatively well constrained and a strong emission source is also revealed in East Asia. Most encouraging is the fact that the inversion does not produce artificial sources in regions where strong emissions are unlikely. 
a) AFEAS/UNFCCC/CIESIN, a priori

b) AFEAS/EDGAR, a priori

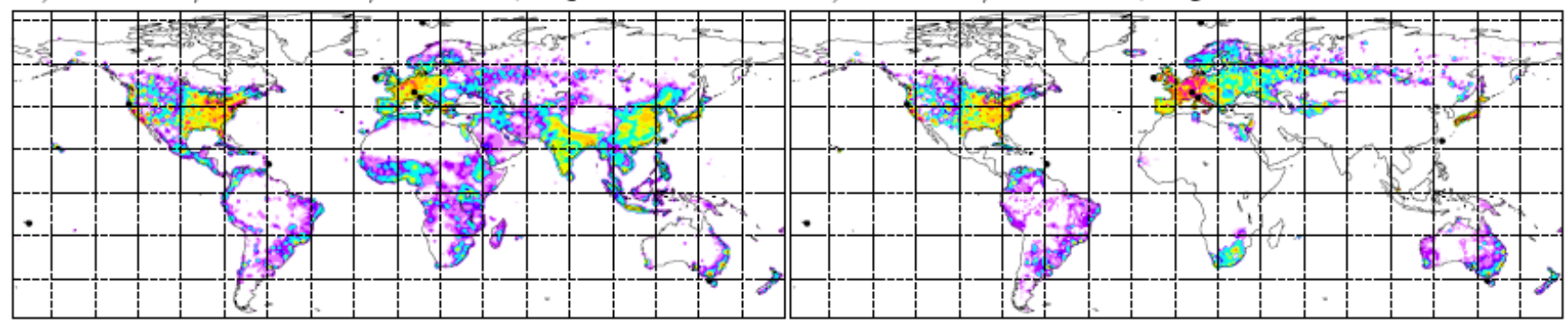

c) AFEAS/UNFCCC/CIESIN, a posteriori

d) AFEAS/EDGAR, a posteriori

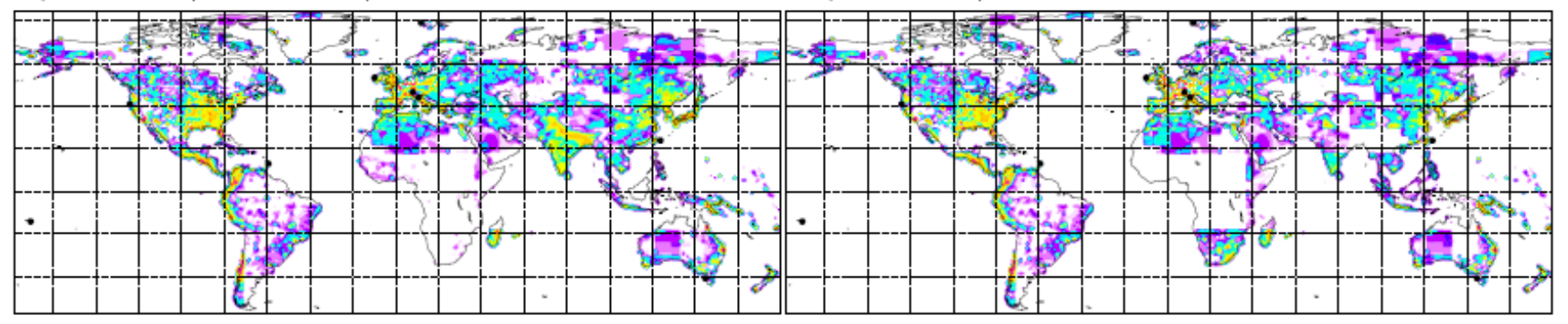

e) Zero, invariable unc., a posteriori

f) AFEAS/UNFCCC/CIESIN/w ocean, a posteriori

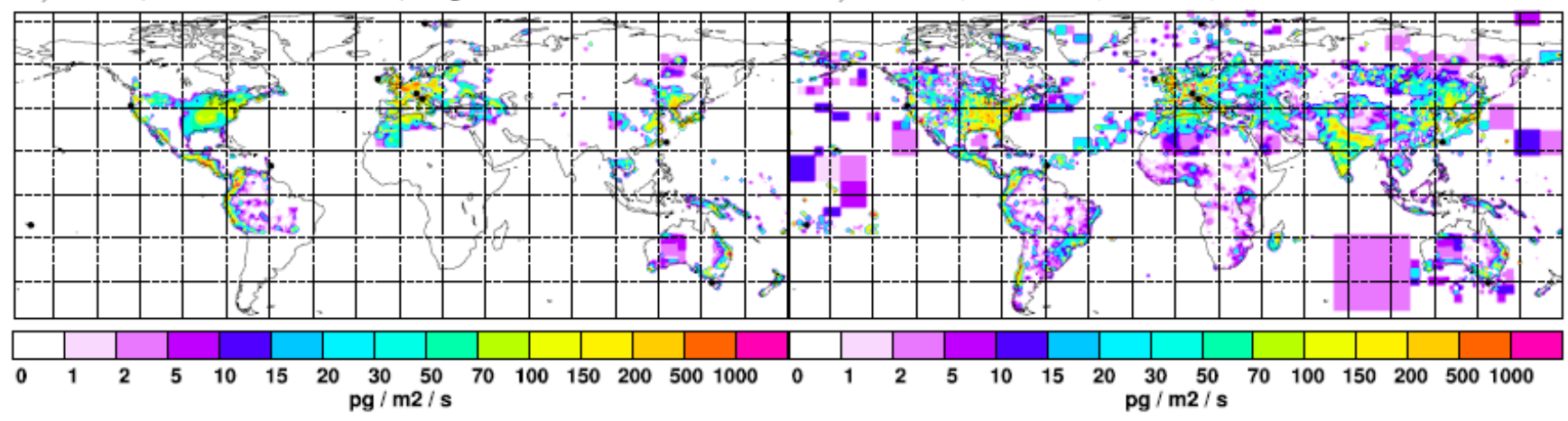

Fig. 5. Distribution of HFC-134a emissions for different a priori assumptions: a priori based on AFEAS/UNFCCC/CIESIN distribution (a), a priori based on EDGAR distribution (b), a posteriori using AFEAS/UNFCCC/CIESIN distribution as a priori (c), a posteriori using EDGAR distribution as a priori (d), a posteriori using zero emissions as a priori (e), a posteriori using AFEAS/UNFCCC/CIESIN distribution as a priori but allowing the inversion to also produce non-zero emissions over the oceans (f). Measurement sites are marked with black dots.

For the zero a priori emission scenario, we also tested how strongly the inversion results depend on the assumed emission uncertainties. In our standard inversion, the uncertainty is $40 \%$ of the emission value in a grid box or $100 \%$ of the global mean emission flux, whichever is larger (for the zero a priori emission scenario, the AUC uncertainties were used). As an alternative, we tested a spatially invariable uncertainty of $200 \%$ of the global mean emission flux (Fig. 5e). The continental total a posteriori values for the two uncertainty scenarios are almost identical (Table 3), except for South America where the masurement constraint is weak. The regional emission distribution within the continents is also similar for both scenarios but the patterns are smoother when using the invariable emission uncertainty.

The influence of the emission uncertainty on the inversion result was also tested for the AUC a priori. Using the spa- tially invariable uncertainty leads to higher total emissions (Table 3). This is a result of the inversion not being able to sufficiently reduce the source strengths in high-emission regions. In high-emission grid cells, the invariable uncertainty is a too small fraction of the a priori source and, thus, the emissions are bound too tightly to their a priori values. The changes (a posteriori minus a priori) in the HFC-134a emission distribution are spatially more homogeneous when using the invariable emission uncertainty than when using a variable emission uncertainty (Fig. 6). For instance, with the invariable uncertainty, emissions are reduced by the inversion almost all over the USA. In contrast, with the variable uncertainty, large reductions are made at the east coast, with a more variable pattern of small increases and decreases elsewhere in the USA. 
a) variable uncertainty

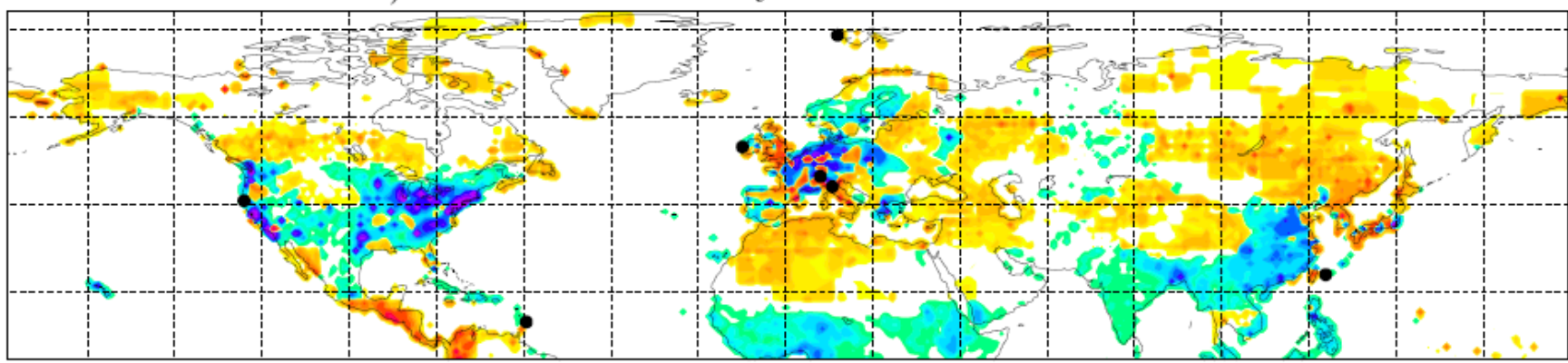

b) invariable uncertainty
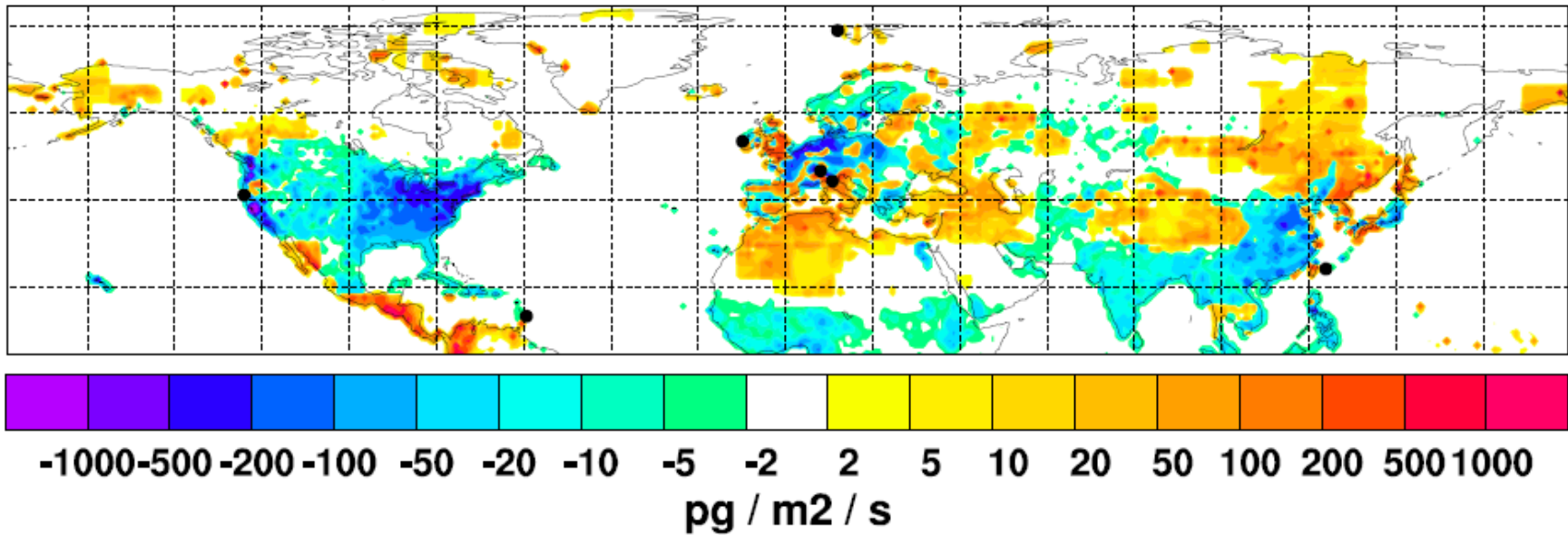

Fig. 6. Changes made by the inversion in the HFC-134a emissions (a posteriori minus a priori) for the AFEAS/UNFCCC/CIESIN a priori when using a variable emission uncertainty (a) and when using a spatially invariable emission uncertainty (b).

Our default setup ignores boxes where more than $99 \%$ of the area is covered by water or ice. Allowing the inversion, using the AUC a priori emissions, to also produce emissions there, provides another check on the quality of the inversion. Although some spurious emissions can be found over the oceans in this case (Fig. 5f), their source strengths are all very low. In contrast, with the exception of South America which is poorly constrained by measurement data, the emissions over the continents remain very similar to our default setup (Table 3).

\subsection{Station-specific error statistics}

Another way to look at the inversion results is to compare a priori and a posteriori errors at different stations for our default inversion using the AUC a priori (Table 2). At stations that are not too far from source regions (Cape Grim, Mace Head, Trinidad Head, Hateruma) relative error reductions $\left(1-E^{b} / E^{a}\right.$ in Table 2$)$ between $25 \%$ and $55 \%$ are achieved. At more remote stations such as Zeppelin and Barbados, errors are reduced by around $15 \%$. At Samoa, the error reduction is marginal. This station is not influenced by sources on the time scale of $20 \mathrm{~d}$ included in our method (see Fig. 1); thus it cannot make a contribution to the in- version. The European mountain stations Jungfraujoch and Monte Cimone have the highest observed values and largest errors, though the tail of the errors has already been clipped. In spite of this, only error reductions of 5\% and, respectively, $9 \%$, are achieved. The reasons for this behaviour have already been discussed in Sect. 4.6.

At most stations, the variability and trend in the baseline explains a substantial fraction of the observed HFC-134a variations, shown as the squared Pearson correlation coefficient $r_{b l}^{2}$ between the a priori baseline and the observed concentrations in Table 2 (results using the a posteriori baseline are nearly identical). $r_{b l}^{2}$ is highest for remote stations (e.g., $r_{b l}^{2}=0.94$ for Zeppelin) where events with transport from source regions on the time scale of $20 \mathrm{~d}$ are rare, intermediate at stations not too far from source regions (e.g., $r_{b l}^{2}=0.44$ for Mace Head) where short-term variability is large, and lowest at the mountain stations where short-term variability dominates (e.g., $r_{b l}^{2}=0.03$ for Jungfraujoch).

Variability in the excess of the observed values over the baseline is mainly the result of transport events. A correlation analysis of the excess with the simulated emission contributions from the last $20 \mathrm{~d}$ reveals to what extent these events are captured by the model. This was done using both the a priori 
$\left(r_{e a}^{2}\right.$ in Table 2) and a posteriori model results $\left(r_{e b}^{2}\right.$ in Table 2). This analysis confirms the previous finding that the transport model has no explanatory power at the remote station Samoa $\left(r_{e b}^{2}=0.03\right)$. The model also performs poorly at the mountain station Jungfraujoch $\left(r_{e b}^{2}=0.04\right)$, partly because of some "incurable" large errors, which were used with a reduced weight in the inversion but are included in the calculation of the correlation coefficients. The situation is a little better at the Monte Cimone mountain site $\left(r_{e b}^{2}=0.16\right)$ where the inversion also results in an improvement of the correlation. The model performs much better at the other sites. At Mace Head, it can even explain $74 \%$ of the observed short-term variance.

The correlations between observations and model results (i.e., baseline plus $20 \mathrm{~d}$ source contributions, $r_{a}^{2}$ and $r_{b}^{2}$ in Table 2) are high at all flatland stations (74-95\% of the variance in the observations explained by the a posteriori model results). Only at the mountain stations Jungfraujoch (11\%) and Monte Cimone (39\%), the observations cannot be explained well.

Figure 7 shows two examples for time series of the observations and inversion results for the stations Mace Head and Trinidad Head where substantial error reductions could be achieved by the inversion. At both stations, the a priori concentrations are reduced, quite substantially so in the case of Trinidad Head where also the baseline is shifted upward to compensate for the reduced source contributions from the $20 \mathrm{~d}$ transport. At Mace Head, even the a priori simulation captures the majority of the transport episodes, and the a posteriori results show excellent agreement with the measurements.

\subsection{Tests with a subset of the data}

To investigate how sensitive the inversion result is to the availability of data from different stations, we repeated the inversion using the AUC a priori information but in one case we removed all data from the Mace Head station and in another case we removed all data from the mountain stations Jungfraujoch and Monte Cimone. The results are compared in Fig. 8 to the inversion using the full data set by showing the increments to the a priori caused by the inversion. Stations outside Europe were kept in the inversion but have a small influence on the results for Europe. The total European emissions are very similar in all three a posteriori cases (26.4, 28.0 and $24.4 \mathrm{kt} / \mathrm{yr}$ for the default inversion, the case without Mace Head data and the case without Jungfraujoch and Monte Cimone data) and are all higher than in the a priori AUC inventory $(24.2 \mathrm{kt} / \mathrm{yr})$. This shows that the measurement data from the different stations are quite consistent with each other in constraining the European total emissions despite the modeling problems at the mountain stations. A similar experiment done with the $\mathrm{AE}$ a priori, which has a three times larger European total emission than the AUC a priori yielded similar a posteriori results, showing that the small differences in the a posteriori total European source strength
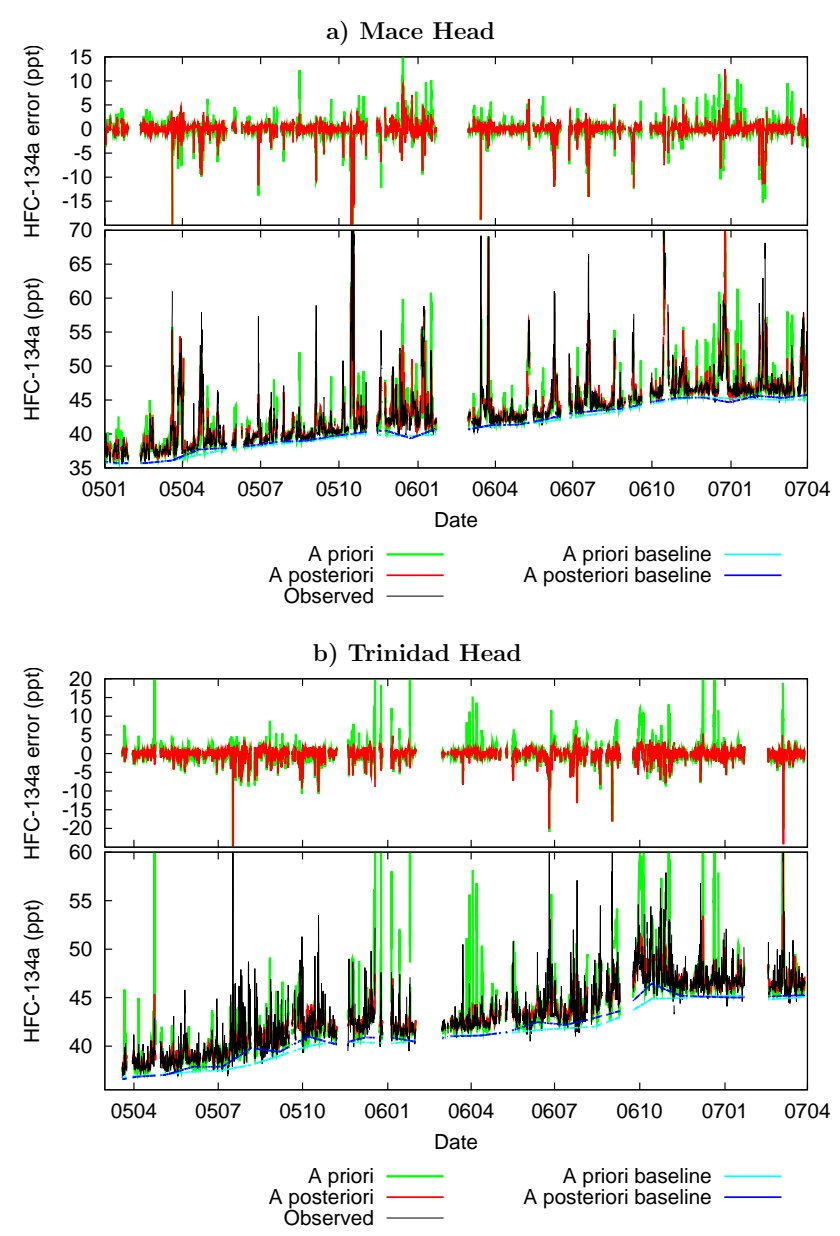

Fig. 7. Time series of HFC-134a at Mace Head (a) and Trinidad Head (b) obtained with the standard inversion setup using the AFEAS/UNFCCC/CIESIN a priori. Shown are the a priori (green line) and a posteriori (red line) results, the a priori (cyan line) and a posteriori (blue line) baseline, as well as the observations (black line). The lower panels show the observed and simulated HFC-134a mixing ratios, the upper panels the corresponding model errors.

are not the result of binding the inversions too tightly to the a priori. In fact, substantial corrections to the a priori occur on the regional scale. These corrections are broadly consistent between the three different inversions shown in Fig. 8, resulting in increases over the United Kingdom, Southern Europe and Eastern Europe, and in small regions in Central Europe, and substantial decreases over large parts of Central Europe, Scandinavia and around Moscow. This encouraging result suggests that even the data from the mountain stations are valuable in guiding the inversion on the regional scale. However, notice also that the removal of data from Mace Head has a stronger impact on the inversion than the removal of both Jungfraujoch and Monte Cimone data, a consequence of the lower model skill for the mountain stations. There are also some inconsistencies between the inversion results 
a) Mace Head removed

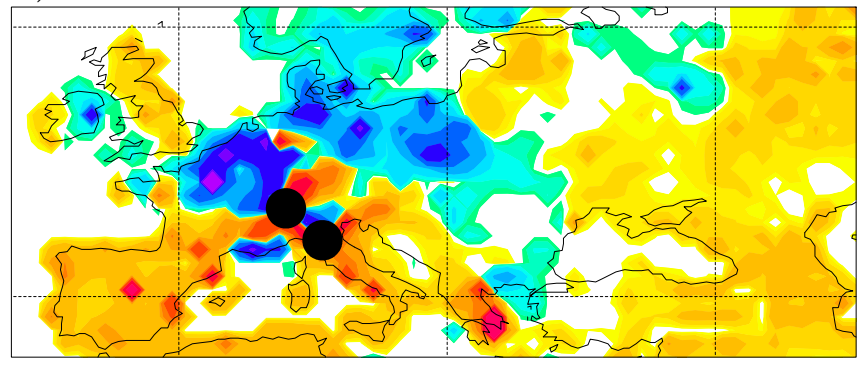

c) all stations

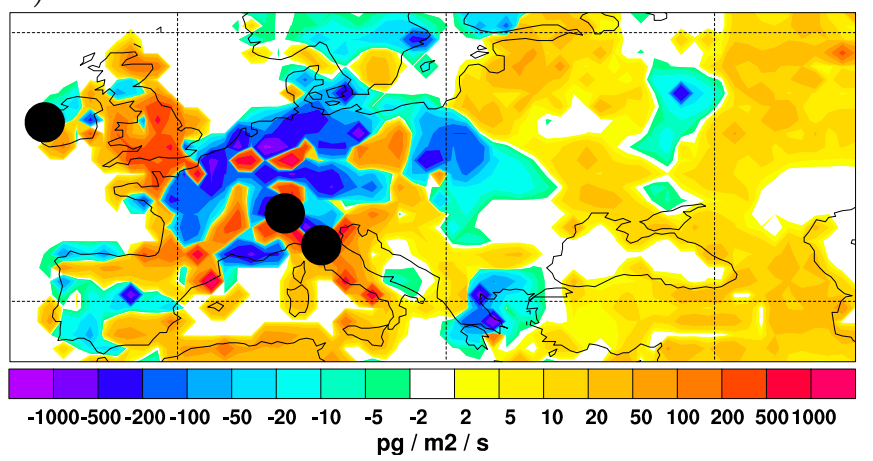

b) Jungfraujoch, Mt. Cimone removed

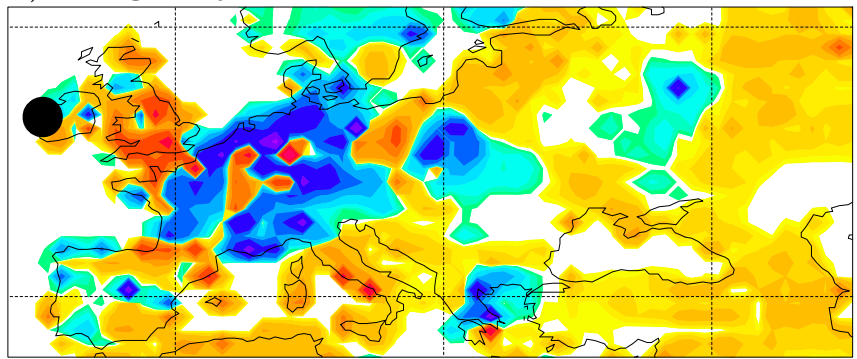

d) AFEAS/UNFCCC/CIESIN, a priori

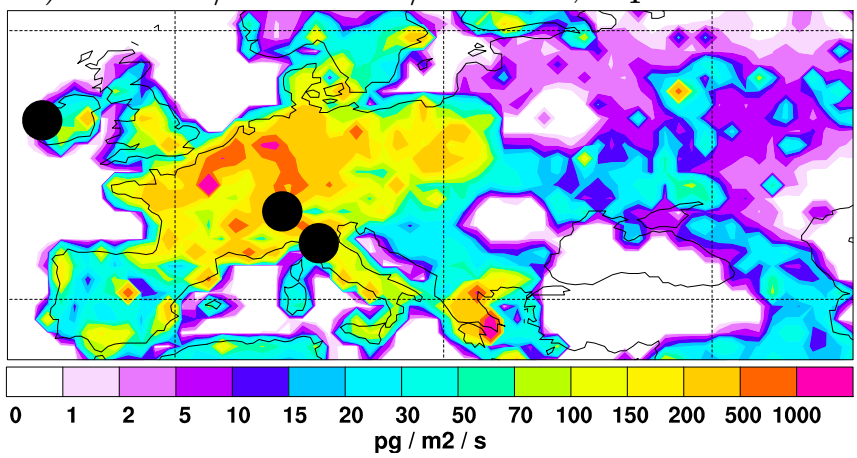

Fig. 8. Sensitivity of the a HFC-134a inversion result to the removal of data. Shown are the changes (a posteriori minus a priori) of the HFC-134a emissions when using all stations except Mace Head (a), all stations except Jungfraujoch and Monte Cimone (b), all stations (d), as well as the a priori emission distribution (d). The lower left color bar refers to all difference plots (panels a-c), whereas the lower right color bar only refers to panel d. Measurement stations are marked with black dots.

but they are mostly restricted to individual grid boxes. For instance, emissions are increased over Madrid when Mace Head data are removed but decreased in the other cases, and the relatively large changes made to the emissions in Central Europe deviate somewhat in location between the different experiments.

Another inversion experiment was done using only data from Jungfraujoch, the station with the poorest model performance. Also data from stations outside Europe were removed. The corrections to the a priori were much smaller in this case but the patterns were broadly consistent with the other results, showing for example emission increases in the United Kingdom and Eastern Europe.

In summary, our sensitivity experiments show that the inversion algorithm is working properly as intended and produces consistent results both for idealized and realistic setups. In the following, we will apply the algorithm to determine the emissions of HFC-134a, HFC-152a and HCFC-22. While our inversion algorithm at present does not yield formal uncertainties of the a posteriori emission fluxes, from the range of results obtained in the sensitivity experiments we subjectively estimate that they are accurate to within better than $20 \%$ for Europe and to within $30 \%$ for other regions well constrained by measurements (North America, large parts of Asia). For smaller regions (e.g., individual small countries), errors may be larger. Future work should consider both a better characterization of the a priori uncertainties of the emission fluxes, as well as an error propagation to yield corresponding uncertainties also of the a posteriori results.

\section{HFC inversion results}

\subsection{HFC-134a}

HFC-134a inversion results for our reference case using the AFEAS/UNFCCC/CIESIN a priori were presented in detail already in Sect. 5 and are further discussed here. To facilitate interpretation, we show results from inversions done separately for the years 2005 and 2006, and we also report totals for some selected countries that are big enough to be resolved by our model grid. The results must be interpreted cautiously where large emissions occur near borders and, thus, attribution of the gridded emissions to a country is somewhat problematic (e.g., Canada, Germany). Both for the a priori as well as for the a posteriori results, total HFC-134a emissions increase from 2005 to 2006 (see Table 4). However, while the a priori emissions increase everywhere (no UNFCCC countryspecific information was available for years after 2005 when this work was done), the a posteriori emissions increase in Europe (mostly in Eastern Europe) and Asia (especially in 
Table 4. Regional emissions (kt/yr) for the years 2005 and 2006 and the total period with available data (January 2005 to March 2007) for HFC-134a, HFC-152a, and HCFC-22. Results for South America and Africa are not reported because of insufficient constraints by measurement data. Global totals are less affected by errors for South America and Africa and are shown.

\begin{tabular}{|c|c|c|c|c|c|c|c|c|c|c|}
\hline \multirow[t]{2}{*}{ Species } & \multicolumn{2}{|c|}{ North America } & \multicolumn{2}{|c|}{ Europe } & \multicolumn{2}{|c|}{ Asia } & \multicolumn{2}{|c|}{ Australia } & \multicolumn{2}{|c|}{ Total } \\
\hline & prior & posterior & prior & posterior & prior & posterior & prior & posterior & prior & posterior \\
\hline HFC-134a, all data & 65 & 43 & 24 & 26 & 41 & 46 & 2 & 7 & 145 & 156 \\
\hline HFC-134a, 2005 & 61 & 41 & 23 & 24 & 38 & 42 & 2 & 5 & 136 & 130 \\
\hline HFC-134a, 2006 & 68 & 38 & 25 & 27 & 42 & 44 & 2 & 5 & 150 & 140 \\
\hline HFC-152a, all data & 11.5 & 15.6 & 3.3 & 4.0 & 7.0 & 10.9 & 0.0 & 0.6 & 23.8 & 37.0 \\
\hline HFC-152a, 2005 & 11.2 & 12.3 & 3.2 & 3.5 & 6.8 & 9.6 & 0.0 & 0.4 & 23.0 & 28.9 \\
\hline HFC-152a, 2006 & 11.8 & 15.1 & 3.3 & 3.9 & 7.1 & 9.8 & 0.0 & 0.2 & 24.3 & 33.4 \\
\hline HCFC-22, all data & 62 & 80 & 13 & 24 & 244 & 149 & 1 & 12 & 346 & 333 \\
\hline HCFC-22, 2005 & 60 & 53 & 12 & 24 & 234 & 133 & 1 & 9 & 332 & 251 \\
\hline HCFC-22, 2006 & 64 & 62 & 13 & 23 & 249 & 146 & 1 & 7 & 354 & 300 \\
\hline
\end{tabular}

China) but decrease in North America. The increase in Europe is a continuation of the upward trend seen also in the UNFCCC data until 2005, while the decrease in North America (due to a decrease in the USA, see Table 5) could indicate a trend reversal. UNFCCC data for the USA and Canada indeed show a leveling-off between 2004 and 2005 of the previously positive emission trend. Our a posteriori emissions for the USA of $35 \mathrm{kt} / \mathrm{yr}$ (28 kt/yr) for 2005 (2006) are furthermore only $61 \%(50 \%)$ of the UNFCCC value. They agree very well with the even somewhat lower values of Millet et al. (2009) who obtained 27 (range of 12-39) kt/yr using aircraft measurement data from the years 2004 and 2006 and a halocarbon-carbon monoxide ratio method to determine the USA emissions.

For Europe, the a posteriori emissions are somewhat higher than the industry-based a priori emissions and suggest a $13 \%$ increase from 2005 to 2006 . In contrast, O'Doherty et al. (2004) found for several periods (latest period 20002002) that emissions derived from simulations with the NAME model and an inverse algorithm were about a factor 2 smaller than the industry-based value. If both model-derived values are correct, this could indicate delayed emissions due to lower leakage rates of HFC-134a, which is mainly used in refrigeration and air-conditioning. More likely, however, the a posteriori emissions from O'Doherty et al. (2004) are too low, especially since their European emissions are only $12 \%$ of their reported global emissions, which seems low. Furthermore, Reimann et al. (2004) derived much higher European emissions of $23.6 \mathrm{kt} / \mathrm{yr}$ for the same period (2000-2002), almost identical to our estimate for 2005 and 2006. Still, our a posteriori source distribution in Europe is quite similar to that shown by O'Doherty et al. (2004), lending confidence to both approaches. The source distribution is, however, very different from the potential source regions shown by Reimann et al. (2008) and Maione et al. (2008) based on statistical analyses of back trajectories and HFC-134a data from the mountain sites Jungfraujoch and Monte Cimone. We attribute this
Table 5. HFC-134a emissions (kt/yr) from UNFCCC for the year 2005 and a posteriori inversion results for selected countries for the years 2005 and 2006. Estimated uncertainties of the a posteriori values are generally $20-30 \%$ but may be somewhat larger for countries with substantial emissions close to borders with other countries (e.g., Germany). Uncertainties in the relative changes from the year 2005 to 2006 , however, are likely to be only about $20 \%$ since the geometry of the observation network has not changed between the years.

\begin{tabular}{lrrr}
\hline Country & UNFCCC & 2005 & 2006 \\
\hline USA & 56.9 & 34.8 & 28.1 \\
Canada & 2.2 & 3.3 & 3.5 \\
France & 5.1 & 5.6 & 5.1 \\
Germany & 4.0 & 2.0 & 2.3 \\
Ireland & 0.2 & 0.3 & 0.3 \\
Italy & 1.8 & 2.4 & 3.9 \\
Poland & 1.7 & 0.9 & 1.4 \\
Spain & 1.6 & 2.1 & 2.1 \\
United Kingdom & - & 1.9 & 1.8 \\
Russia & - & 6.4 & 5.6 \\
China & - & 9.8 & 11.9 \\
Japan & 3.5 & 5.3 & 4.0 \\
Australia & 1.9 & 4.9 & 4.5 \\
\hline
\end{tabular}

to artifacts in their trajectory statistics, which are likely to occur especially in regions not frequently passed by trajectories.

While many western European countries (e.g., France, Ireland, Spain, United Kingdom) had constant or slightly decreasing emissions from 2005 to 2006, emissions in some southern (e.g., Italy) and eastern (e.g., Poland) European countries increased (Table 5). In general, there is relatively good agreement between UNFCCC reported emissions and our a posteriori emissions for the year 2005 for most European countries. 
For Asia, between 2005 and 2006 we find an increase of emissions in China and a decrease in Japan (Table 5). According to UNFCCC, emissions in Japan peaked in 2003 and decreased by $25 \%$ until 2005 . Our results confirm decreasing emissions in Japan but the 2005 total is $50 \%$ higher than the UNFCCC total. For China, we obtain annual emissions of 9.8 and $11.9 \mathrm{kt} / \mathrm{yr}$ for the years 2005 and 2006, respectively, substantially more than the $3.9 \mathrm{kt} / \mathrm{yr}$ reported by Yokouchi et al. (2006) for the period May 2004-May 2005, which was derived using Hateruma HFC-134a to carbon monoxide ratios and a - likely too low - estimate of Chinese carbon monoxide emissions. Our results indicate that China is now a substantial emitter of HFC-134a with a $20 \%$ growth in emissions from 2005 to 2006. For Australia, our a posteriori emissions for 2005 and 2006 are about a factor 2.5 larger than the industry-based a priori (see Table 4 and discussion below for possible explanation).

\subsection{HFC-152a}

HFC-152a has an estimated atmospheric lifetime of $1.55 \mathrm{yr}$ (Greally et al., 2007) and is used predominately in foamblowing and aerosol spray applications (Ashford et al., 2004b). For HFC-152a, the a priori emission data were calculated slightly differently than for HFC-134a. As no global emission data from AFEAS are available, we used projections from Ashford et al. (2004b) for 2005-2007 directly (i.e., without adjustment to AFEAS emissions). Furthermore, UNFCCC country total emissions are available for fewer countries than for HFC-134a. Where available, we used this information. Data for the USA - the largest emitter of HFC-152a, according to Ashford et al. (2004b) - are missing for confidentiality reasons. A distribution of emissions according to the world population distribution would definitely lead to an underestimation of HFC-152a emissions in the USA (about $1 \mathrm{kt} / \mathrm{yr}$ ). Inversion experiments done with such a low a priori value for the USA lead to a more than four-fold increase of emissions in the USA and unrealistically high emissions in border regions of Canada, as the inversion algorithm is trying to compensate for far too low USA emissions. To bring the a priori estimate closer to the suspected real emissions, we therefore assumed an annual emission of $10 \mathrm{kt} / \mathrm{yr}$ in the USA, about $40 \%$ of the global emissions.

The inversion results in a substantial increase $(55 \%$ for the whole period) of global HFC-152a emissions relative to the a priori emission from Ashford et al. (2004b) (see Table 4 and Fig. 9). The relative increase is larger for the full period than for the individual years because the stronger constraint from the larger measurement data set can drive the a posteriori solution further away from the a priori emissions. This effect is especially evident in this case of HFC-152a where the a priori emissions are systematically too low in all continents. Since the solution is bound towards a too low a priori, it is likely that our inversion results (particularly for the indi-
Table 6. HFC-152a emissions ( $t / y r)$ from UNFCCC for the year 2005 and a posteriori inversion results for selected countries for the years 2005 and 2006 .

\begin{tabular}{lrrr}
\hline Country & UNFCCC & 2005 & 2006 \\
\hline USA & - & 10100 & 12509 \\
Canada & 918 & 1470 & 1592 \\
France & 314 & 626 & 479 \\
Germany & 781 & 434 & 459 \\
Ireland & 7 & 15 & 18 \\
Italy & - & 259 & 388 \\
Poland & 24 & 20 & 22 \\
Spain & 170 & 351 & 175 \\
United Kingdom & - & 88 & 76 \\
Russia & - & 1185 & 1123 \\
China & - & 3162 & 3655 \\
Japan & 1217 & 1532 & 1267 \\
Australia & - & 357 & 221 \\
\hline
\end{tabular}

vidual years) are actually a lower estimate of the true global source strength.

Greally et al. (2007) calculated the global HFC-152a source from AGAGE data and an inverse 12-box model. They found a more rapid (and accelerating) increase of HFC152a emissions than reported by Ashford et al. (2004b) from industry data. For the year 2004, Greally et al. (2007) reported a source strength of $28.5 \mathrm{kt}$, compared to only $21.9 \mathrm{kt}$ from Ashford et al. (2004b). Our results confirm this stronger source and also indicate that emissions have grown more rapidly from 2005 to 2006 than the industry-based estimate of Ashford et al. (2004b).

The inversion increases the emissions in all continents (see Table 4 and Fig. 9), even in North America, where high a priori emissions of $10 \mathrm{kt} / \mathrm{yr}$ for the USA alone were used. Millet et al. (2009), based on their aircraft data, reported somewhat lower emissions for the USA $(7.6 \mathrm{kt} / \mathrm{yr}$ with a range of $5.7-$ $9.7 \mathrm{kt} / \mathrm{yr})$ than what we have obtained $(10.1$ and $12.5 \mathrm{kt} / \mathrm{yr}$ for 2005 and 2006, respectively). However, most of their data was from the year 2004 and, given the strong trend, can still be considered in good agreement. The smallest increases occur in Europe where many countries have reported their emissions to UNFCCC and our a priori estimate should be most accurate. Most of these increases occur in Southern Europe (see Fig. 9c), especially in Italy and in some regions of Spain. European emissions derived by the inversion increased from 2005 to 2006, whereas emissions reported by the European Union decreased from 2003 to 2005. Increasing emissions higher than reported by the EU countries were already found by Greally et al. (2007) using inversions based on another LPDM and Reimann et al. (2004) using measurement data from Jungfraujoch. There is some agreement in regional emission patterns in Europe between our results and those reported by Greally et al. (2007), Maione et al. (2008) and Reimann et al. (2008). 
a) a priori

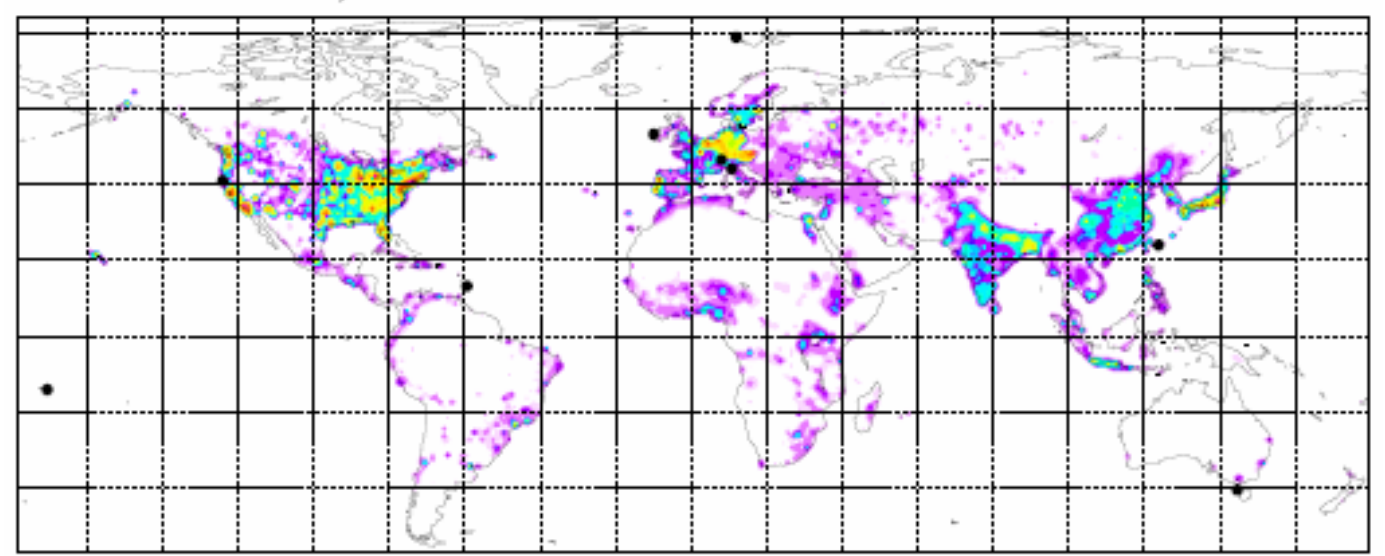

b) a posteriori
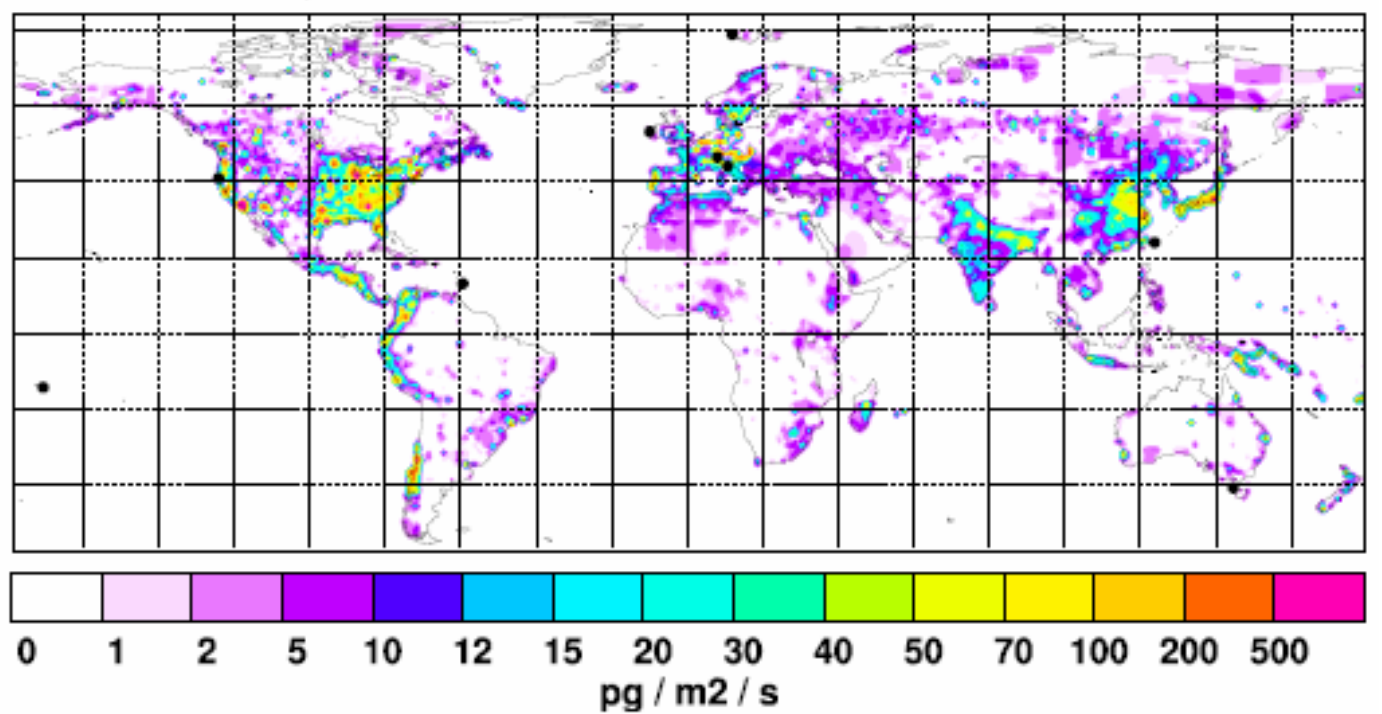

c) a posteriori minus a priori

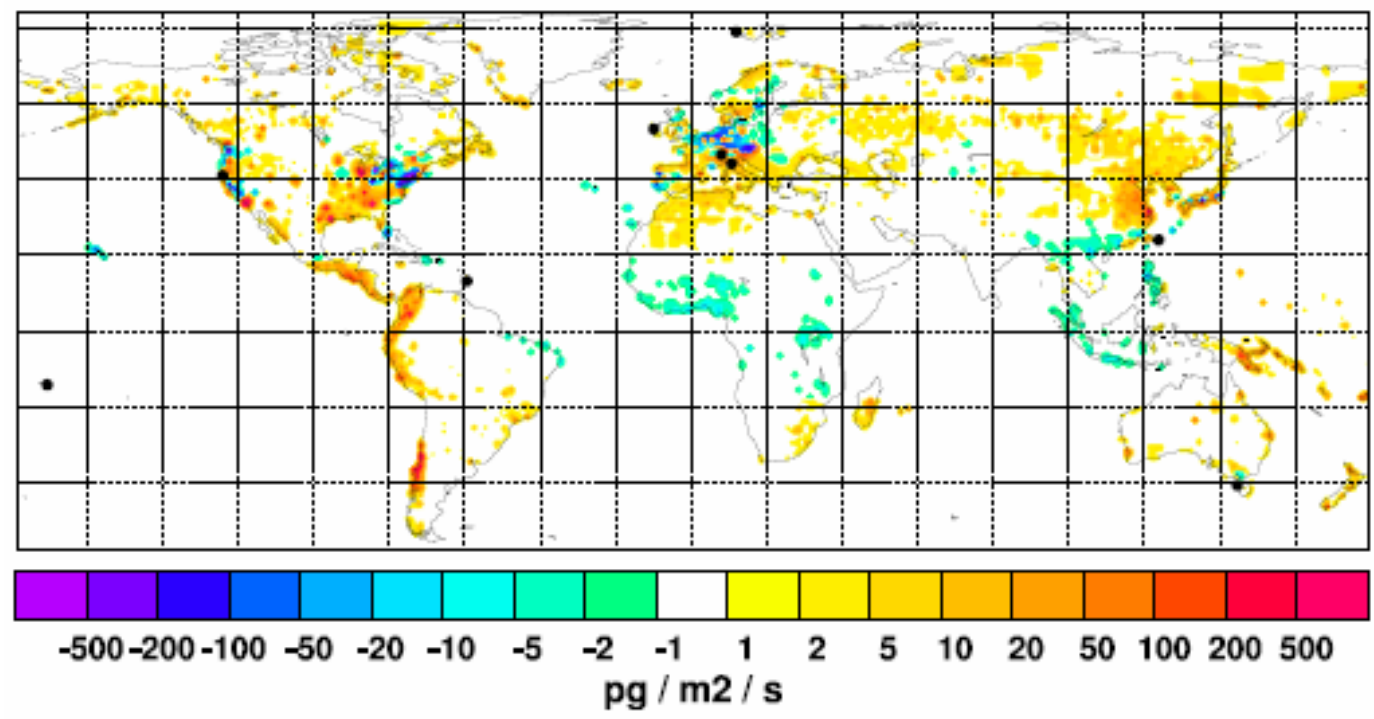

Fig. 9. A priori (a), a posteriori (b) and a posteriori minus a priori (c) emissions of HFC-152a using the full measurement data set. Measurement stations are marked with black dots. 
The inversion increases the emissions in Asia by about $50 \%$, with a doubling of the a priori emissions in China (see Fig. 9) and a 16\% increase from 2005 to 2006 (see Table 6). Our estimated Chinese HFC-152a emissions of 3.2-3.7 kt/yr are in good agreement with the $4.3 \mathrm{kt} / \mathrm{yr}$ recently reported by Yokouchi et al. (2006) for the period May 2004 to May 2005.

HFC-152a emissions in Australia are relatively small (ca. 200-600 t/yr, depending on period) but significantly larger than the 5-10 t/yr reported by Greally et al. (2007). Figure 10 shows time series of HFC-152a for the Cape Grim station in Tasmania. HFC-152a concentrations are very low and the measurements show a lot of variability, which partly appear to be associated with instrumental noise and probably the advection of air masses with variable background but without recent emission input, which makes the inversion difficult. However, some of the longer-lasting variations require an increase by an order of magnitude of the low a priori emission for Australia ( $28 \mathrm{t} / \mathrm{yr})$ in order to be captured by the model. While it is possible that the a priori emissions for Australia are too low, such a large increase is not consistent with HFC consumption data for Australia. Thus, the large a posteriori emissions in Australia point towards a problem of our inversion setup. One problem is that Australia is constrained only by a single station, Cape Grim, which is located to the south of the emission sources. At the same time, the halocarbon background concentrations increase with latitude and, in particular, are much higher in the northern than in the Southern Hemisphere. Thus, air masses transported across Australia southward to the station would tend to be associated with elevated concentrations, even without the additional emission input from Australia. In such a situation, the inversion algorithm would attempt to attribute the observed concentration increase to emissions in Australia. This effect could potentially overshadow actual emissions in Australia especially for substances where Australian emissions are very low compared to those in the Northern Hemisphere. Given the present geometry of the observation networks, our algorithm is obviously not sensitive enough to quantify the relatively small emission source in Australia. The problem may be exacerbated by the point-like nature of emission sources in Australia (e.g., those in Melbourne), which are not resolved by our inversion grid.

\subsection{HCFC-22}

HCFC-22 is the most abundant of the hydrochlorofluorocarbons measured in the atmosphere and has a lifetime of about $12 \mathrm{yr}$ (O'Doherty et al., 2004). It is used in refrigeration, as a foam-blowing agent, and it is also used for the production of fluoropolymers (McCulloch et al., 2006). Regarding our a priori emissions, we used global annual HCFC-22 emissions from Ashford et al. (2004b). Country totals for the annual consumption of HCFCs (not only HCFC-22) in the year 2006, expressed in terms of the ozone-depletion potential, are available from the United Nations Environment

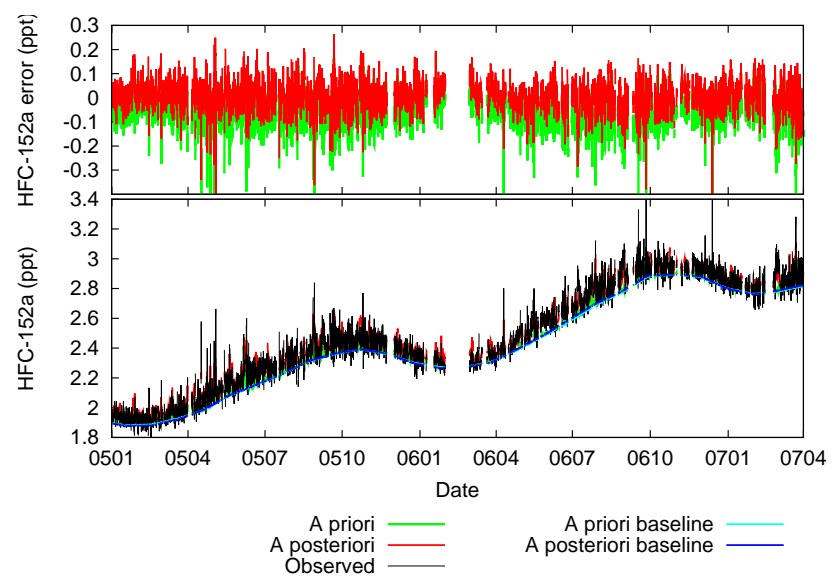

Fig. 10. Time series of HFC-152a in Tasmania. Shown are the a priori (green line) and a posteriori (red line) results, the a priori (cyan line) and a posteriori (blue line) baseline, as well as the observations (black line). The lower panels show the observed and simulated HFC-152a mixing ratios, the upper panels the corresponding model errors.

Programme (http://ozone.unep.org/), see also UNEP (2005). We identified the 22 countries with the largest HCFC consumption which together are responsible for nearly $92 \%$ of reported global emissions. China alone contributed almost $50 \%$ to the global HCFC consumption in 2006, in agreement with the report by McCulloch et al. (2006) of rapidly growing HCFC-22 production in China. Country totals were distributed according to the CIESIN population distribution within the respective countries, and remaining global emissions were also distributed according to population. HCFC22 data from Jungfraujoch were not used because of a known contamination problem.

The global emissions after the inversion (Fig. 11 and Table 4 ) are reduced slightly (by $4 \%, 25 \%$ and $15 \%$ for the full period, the year 2005 and the year 2006, respectively) compared to the a priori total emission. However, there are large regional differences between the a priori and the a posteriori emissions. For instance, emissions in Europe are doubled, emissions in Asia are reduced by about $40 \%$ (largely because of reductions in China) and emissions in Australia are increased by an order of magnitude. The emission increase in Europe can be explained by a time lag between HCFC22 consumption as contained in the UNEP statistics and the actual time of emission occurrence, since reported HCFC22 consumption in Europe is dropping rapidly (a hint of a decrease from 2005 to 2006 is seen in the inversion results). Such a time lag is plausible since HCFC-22 (a refrigerant and foam-blowing agent) is not released to the atmosphere immediately when used. A time lag between reported consumption and emission can also explain the lower a posteriori HCFC22 emissions in Asia since emissions in China are growing rapidly. The large increase for Australia is thought to be an artifact of the method, as discussed above for HFC-152a. 
a) a priori

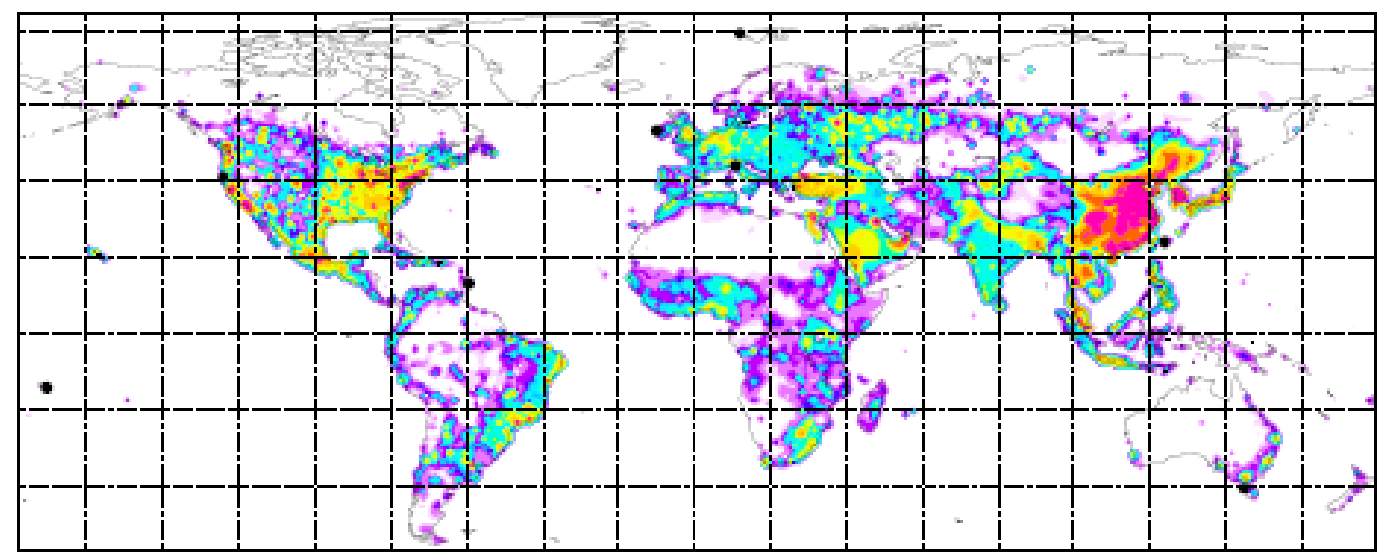

b) a posteriori

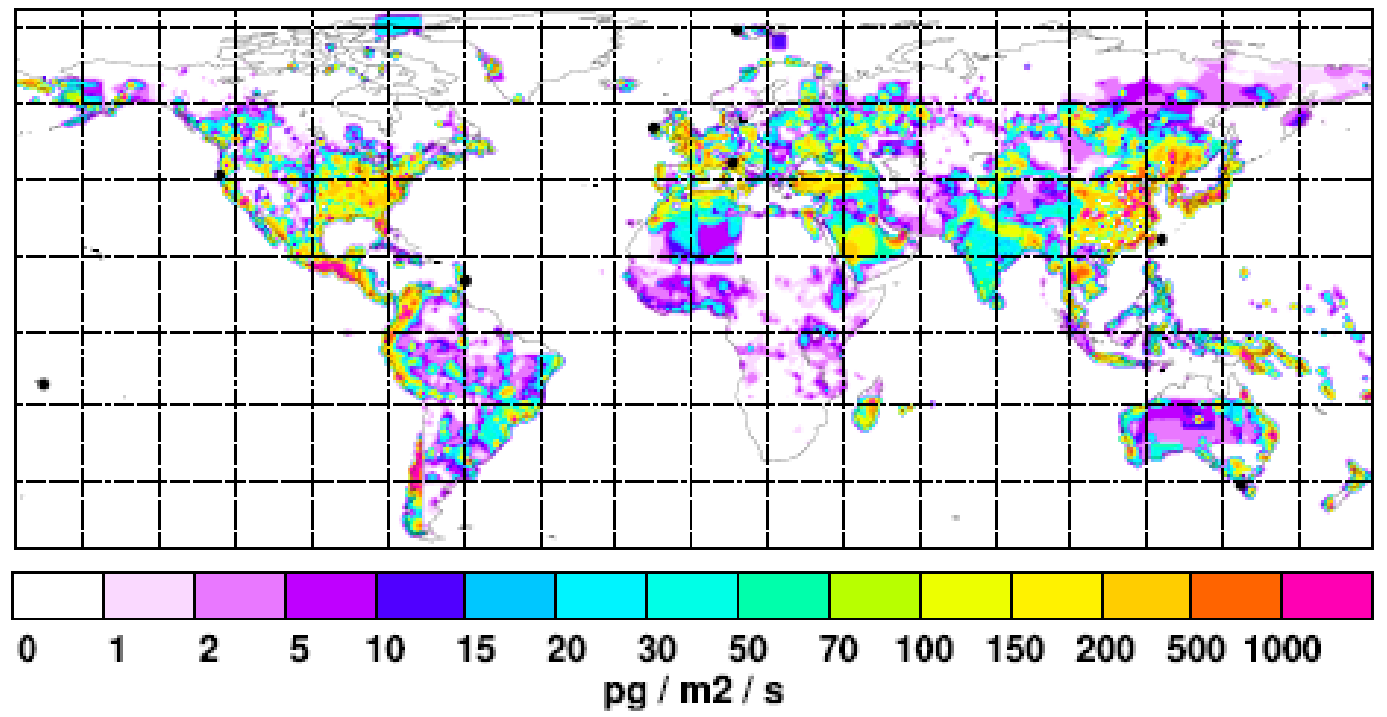

c) a posteriori minus a priori

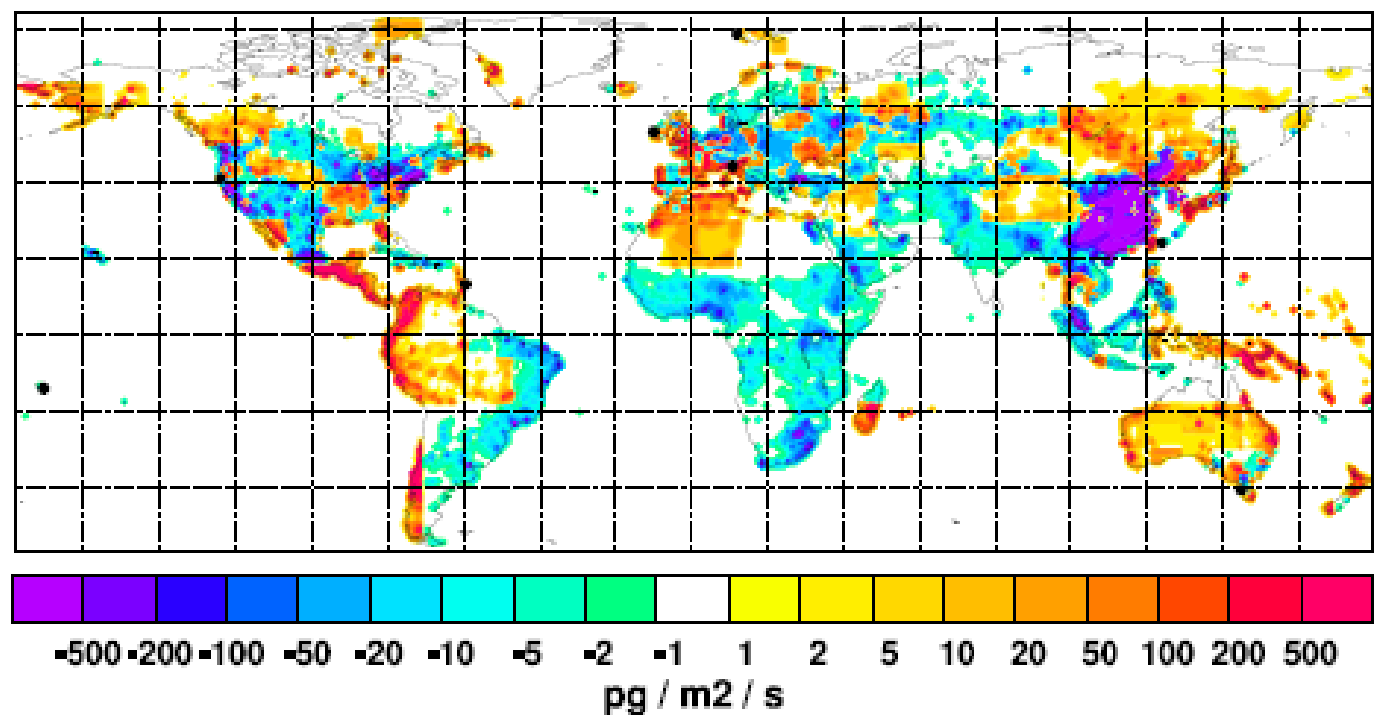

Fig. 11. A priori (a), a posteriori (b) and a posteriori minus a priori (c) emissions of HCFC-22 using the full measurement data set. Measurement stations are marked with black dots. 
Table 7. HCFC-22 emissions ( $t / y r)$ used as the a priori and a posteriori inversion results for selected countries for the years 2005 and 2006. Only total HCFC consumption data are available from UNEP, and no country-specific information was available for the European Union, so data in the "UNEP/a priori" column are based on our disaggregated gridded data.

\begin{tabular}{lrrr}
\hline Country & UNEP/a priori & 2005 & 2006 \\
\hline USA & 44603 & 32864 & 31940 \\
Canada & 5300 & 7170 & 4922 \\
France & 873 & 4527 & 3397 \\
Germany & 879 & 601 & 768 \\
Ireland & 56 & 253 & 254 \\
Italy & 655 & 2821 & 2783 \\
Poland & 482 & 252 & 220 \\
Spain & 463 & 1884 & 1045 \\
United Kingdom & 725 & 1898 & 1813 \\
Russia & 7592 & 10339 & 10159 \\
China & 166119 & 59759 & 70650 \\
Japan & 6966 & 10181 & 7785 \\
Australia & 1027 & 8925 & 7264 \\
\hline
\end{tabular}

For the USA (33 and $32 \mathrm{kt} / \mathrm{yr}$ for 2005 and 2006), there is again a good agreement with the study of Millet et al. (2009) who obtained 46 (21-69) kt/yr based on aircraft data. In Europe, the inversion increases the emissions most strongly in western and Southern Europe (e.g., a factor of 4-5 in France, Italy and Spain, see Table 7), whereas emissions in some regions in Eastern Europe are even decreased (e.g., a factor 2 decrease in Poland). In Asia, the dominant feature is a large reduction by the inversion of emissions in China, whereas emissions in Japan are increased. Regarding the change from 2005 to 2006, the inversion produces a $18 \%$ emission increase for China and a $24 \%$ decrease for Japan, in line with the large reported changes of HCFC consumption in these two countries. Again, this indicates a lag of a few years between the year of reported HCFC-22 consumption and the time of actual emission. Substantial emission increases are also made by the inversion in Central America, which could point towards an underreporting of HCFC consumption there.

\section{Discussion and conclusions}

We have further developed the analytical inversion method of Seibert $(2000,2001)$ to determine the regional and global emissions of long-lived GHGs from concentration measurements. The method is based on $20 \mathrm{~d}$ backward simulations from a number of measurement stations using a Lagrangian particle dispersion model. It objectively determines a timevarying baseline concentration for each station and uses the observed and modeled enhancements over the baseline to improve an a priori emission distribution. The method con- tains a detailed treatment of the uncertainties in the modelmeasurement comparison as well as in the a priori emission field. A propagation of these uncertainties to the a posteriori emission fluxes is left to future development, which will also require an improved knowledge of the a priori emission errors.

We applied the method to HFC-134a, HFC-152a and HCFC-22 measurements obtained at eight stations of the AGAGE and SOGE networks and a Japanese station. Unfortunately, most of the nine stations are not ideally placed for determining regional emission fluxes. Some (e.g., American Samoa) are too remote and are not influenced by emissions on the time scale considered in our model calculations (20 d). As already noted by Mahowald et al. (1997), locating the observing stations closer to the source regions would improve the ability of inversion methods to deduce source information. At the mountain stations (Jungfraujoch, Monte Cimone), the model has big difficulties in reproducing the observed concentration variability because of the complex local meteorology, close-by emission sources, and the episodic transport of pollutants from these local sources. While the data from these stations still help constraining the emissions, the data value for the inversion would increase substantially if the stations were moved to topographically less complex locations while, however, still staying outside the proximity of strong sources. Finally, the global distribution of the stations is not satisfactory. While at least three stations provide direct information on European emissions, not a single station provides a good constraint on the emissions in Africa and large parts of South America (Fig. 1). Also emissions in India, Indonesia and Northern Australia are not well constrained by the data.

For the siting of stations in the future, we recommend that the sources in every continent should be constrained by at least two stations. The first station should be placed downwind of the continental emissions in the main continental pollution outflow, other stations should be placed as far away from the first station as possible to "view" the major source regions from a different angle. This would help the inversion in separating the emission strengths of different regions within the continent. Ideally, the stations should be located either near the coastline or better even on small islands just downwind of the shoreline in areas not strongly influenced by emission sources within about $50-100 \mathrm{~km}$ of the station. Mace Head, Trinidad Head and Hateruma are relatively well placed according to the above criteria but they are not in the main pollution outflow pathway and, thus, sample the continental emissions somewhat too infrequently. A new observatory that is currently being built at Birkenes in southern Norway will hopefully fulfill all the above criteria and, thus, holds the promise of delivering an extremely valuable data set to better constrain regional emissions in Europe. Most urgent, however, would be the addition of stations in tropical areas where constraints are currently missing almost entirely (see Fig. 1): probably on the Maldives to constrain emissions 
from India, at the Pacific and Atlantic coasts of Northern South America to constrain emissions in South America, at the Cape Verde islands to constrain emissions in Africa, or in Northeastern Australia to constrain emissions in Northern Australia and Indonesia. Before deciding on a location, backward model calculations should be done specifically for candidate sites to find out which options would yield the best overall improvement of the global emission sensitivity distribution (Fig. 1). In this context, it could be interesting to make use of backward transport calculations carried out routinely by the Comprehensive Nuclear Test Ban Treaty Organisation (CTBTO/PrepCom) for its global network of radionuclide monitoring stations (Wotawa et al., 2003; Becker et al., 2007). This network is also interesting because at these sites the necessary infrastructure is already available.

When fed with pseudo observations generated by the transport model, our inversion method can reconstruct the emission distribution used for generating the model results almost perfectly (see Fig. 3). Even when noise is superimposed on the data, the emission reconstruction is nearly perfect in areas that are well constrained by the pseudo observations. However, in areas not so well constrained (much of the Southern Hemisphere), the result is tied more closely towards the a priori emission field.

Using real HFC-134a data, we have explored the sensitivity of the method to changes in the a priori emission field and its uncertainties. In well constrained regions (Europe, parts of North America and Asia), the a posteriori emission fields are quite close to each other; however, large differences can occur in the Southern Hemisphere (Fig. 5 and Table 3). Even when using no a priori information (zero a priori emissions), the major emission areas in Europe, North America and eastern Asia can be identified. While the source strengths are too low in this case, due to the regularization constraining the emissions towards zero, the bias for the well-constrained regions is only about $-40 \%$. The method is also relatively robust against the removal of data from individual stations.

One particular problem was identified for Australia, where emissions are constrained by a single station, Cape Grim. This station is located south of the major emission sources, whereas the halocarbon background in the Southern Hemisphere increases towards the north. Thus, southward transport across Australia would be associated with elevated concentrations, even if Australian emissions were zero. At the same time, actual emissions in Australia are so small that their signal can easily be overshadowed by the advection of a varying background, which is erroneously attributed to Australian emissions by the inversion algorithm. This points towards a possible improvement of our inversion algorithm. Instead of specifying a baseline for each individual station, the baseline nodes could be defined for a few latitude bands. The instantaneous baseline at a particular station could then be calculated by considering the correct initial condition at the beginning of each $20 \mathrm{~d}$ particle trajectory. That way, the baseline at a station would depend on the "origin" of an air mass. In the example for Australia, this would mean a higher baseline for transport from the north.

In our inversions for HFC-134a, HFC-152a and HCFC-22, we found that our global a posteriori emissions increased for all three species from 2005 to 2006 . The largest increases (21\%, 16\%, 18\%, respectively) from 2005 to 2006 were found for China, in line with the relatively strong halocarbons emissions in Eastern Asia reported elsewhere (Palmer et al., 2003). In contrast, changes in the emissions in North America and Europe were modest from 2005 to 2006. For Europe, the a posteriori emissions of HFC-134a and HFC152a were slightly higher than the a priori emissions reported to the UNFCCC. For HCFC-22, the a posteriori emissions for Europe were substantially (by almost a factor 2) higher than the a priori emissions, which were based on HCFC consumption data reported to UNEP. Combined with the reported strongly decreasing HCFC consumption in Europe, this suggests a substantial time lag between the reported timing of the HCFC-22 consumption and the actual timing of the HCFC22 emission. Similarly, in China where HCFC consumption is increasing rapidly according to the UNEP data, our a posteriori emissions are only about $40 \%$ of the estimated annual HCFC-22 consumption used for the a priori emissions, revealing a substantial storage of HCFC-22 and potential for future emission in China.

The basic methodology described in this paper can of course be applied to many other substances that have sufficiently long lifetimes to consider them stable during a period on the order of $20 \mathrm{~d}$.

Acknowledgements. We appreciate the comments from two reviewers on the ACPD version of this paper, which helped shaping this final version. We thank Met.no and ECMWF for access to the ECMWF data. P. Seibert acknowledges the support of the Fonds zur Förderung der wissenschaftlichen Forschung (FWF, grant 17924) and the EU-FP6 Network of Excellence ACCENT.

Edited by: L. Carpenter

\section{References}

AFEAS (Alternative Fluorocarbons Environmental Acceptability Study): Production, sales, and emission data for 2005: AFEAS, Arlington, VA, USA, (seewww.afeas.org), 2007.

Ashford, P., Clodic, D., McCulloch, A., and Kuijpers, L.: Emission profiles from the foam and refrigeration sectors comparison with amtospheric concentrations. Part 1: Methodology and data, Intern. J. Refrigeration, 27, 687-700, 2004a.

Ashford, P., Clodic, D., McCulloch, A., and Kuijpers, L.: Emission profiles from the foam and refrigeration sectors comparison with amtospheric concentrations. Part 2: Results and discussion, Intern. J. Refrigeration, 27, 701-716, 2004b.

Becker, A., Wotawaa, G., De Geer, L.-E., Seibert, P., Draxler, R. R., et al.: Global backtracking of anthropogenic radionuclides by means of a receptor oriented ensemble dispersion modelling system in support of Nuclear-Test-Ban Treaty verification, Atmos. Environ., 41, 4520-4534, 2007. 
Chen, Y.-H. and Prinn, R. G.: Estimation of atmospheric methane emissions between 1996-2001 using a 3D global chemical transport model, J. Geophys. Res., 111, D10307, doi:10.1029/2005JD006058, 2006.

Chipperfield, M. and V. Fioletov (Lead Authors): Global Ozone: Past and Present, Chapter 3 in Scientific Assessment of Ozone Depletion 2006, Global Ozone Research and Monitoring ProjectReport No. 50, 3.1-3.58, WMO, Geneva, Switzerland, 2007.

Center for International Earth Science Information Network (CIESIN): Gridded Population of the World: Future Estimates, Socioeconomic Data and Applications Center (SEDAC), Columbia University, Palisades, NY, USA, 2005. Available at http://sedac.ciesin.columbia.edu/gpw (downloaded on 22 April 2008).

Clerbaux, C. and D. Cunnold (lead Authors): Long-Lived Compounds, Chapter 1 in Scientific Assessment of Ozone Depletion 2006, Global Ozone Research and Monitoring Project-Report No. 50, 1.1-1.63, WMO, Geneva, Switzerland, 2007.

Damoah, R., Spichtinger, N., Forster, C., James, P., Mattis, I., Wandinger, U., Beirle, S., and Stohl, A.: Around the world in 17 days - hemispheric-scale transport of forest fire smoke from Russia in May 2003, Atmos. Chem. Phys., 4, 1311-1321, 2004, http://www.atmos-chem-phys.net/4/1311/2004/.

Dunse, B., Steele, P., Wilson, S., Fraser, P., and Krummel, P.: Trace gas emissions from Melbourne Australia, based on AGAGE observations at Cape Grim, Tasmania, 1995-2000, Atmos. Environ., 39, 6334-6344, 2005.

ECMWF, White, P. W. (ed.): IFS Documentation, ECMWF, Reading, UK, 2002.

Eckhardt, S., Breivik, K., Man, S., and Stohl, A.: Record high peaks in PCB concentrations in the Arctic atmosphere due to longrange transport of biomass burning emissions, Atmos. Chem. Phys., 7, 4527-4536, 2007, http://www.atmos-chem-phys.net/7/4527/2007/.

Eckhardt, S., Prata, A. J., Seibert, P., Stebel, K., and Stohl, A.: Estimation of the vertical profile of sulfur dioxide injection into the atmosphere by a volcanic eruption using satellite column measurements and inverse transport modeling, Atmos. Chem. Phys., 8, 3881-3897, 2008,

http://www.atmos-chem-phys.net/8/3881/2008/.

Emanuel, K. A., and Živković-Rothman, M.: Development and evaluation of a convection scheme for use in climate models, J. Atmos. Sci., 56, 1766-1782, 1999.

Enomoto, T., Yokouchi, Y., Izumi, K., and Inagaki, T.: Development of an analytical method for atmospheric halocarbons and its application to airborne observation, J. Jpn. Soc. Atmos. Environ., 40, 1-8, 2005 (in Japanese).

Enting, I.: Inverse Problems in Atmospheric Constituent Transport, Cambridge University Press, Cambridge, UK, 392 pp., 2002.

Forster, C., Stohl, A., and Seibert, P.: Parameterization of convective transport in a Lagrangian particle dispersion model and its evaluation, J. Appl. Meteor. Clim., 46, 403-422, 2007.

Forster, P., Ramaswamy, V., Artaxo, P., Berntsen, T., Betts, R., Fahey, D. W., Haywood, J., Lean, J., Lowe, D. C., Myhre, G., Nganga, J., Prinn, R., Raga, G., Schulz, M., and Van Dorland, R.: Changes in Atmospheric Constituents and in Radiative Forcing, in: Climate Change 2007: The Physical Science Basis. Contribution of Working Group I to the Fourth Assessment Report of the Intergovernmental Panel on Climate Change, edited by:
Solomon, S., Qin, D., Manning, M., Chen, Z., Marquis, M., Averyt, K. B., Tignor, M., and Miller, H. L., Cambridge University Press, Cambridge, UK and New York, NY, USA, 2007.

Greally, B. R., Manning, A. J., Reimann, S., McCulloch, A., Huang, J., et al.: Observations of 1,1-difluoroethane (HFC-152a) at AGAGE and SOGE monitoring stations in 1994-2004 and derived global and regional emission estimates, J. Geophys. Res., 112, D06308, 10.1029/2006JD007527, 2007.

Hartley, D. and Prinn, R.: Feasibility of determining surface emissions of trace gases using an inverse method in a threedimensional chemical transport model, J. Geophys. Res., 98, 5183-5197, 1993.

Kasibhatla, P., Heimann, M., Rayner, P., Mahowald, N., Prinn, R., and Hartley, D. (eds.): Inverse Methods in Global Biogeochemical Cycles, American Geophysical Union (AGU) Geophysical Monograph Series, 114, 324 pp., 2000.

Mahowald, N. M., Prinn, R. G., and Rasch, P. J.: Deducing $\mathrm{CCl}_{3} \mathrm{~F}$ emissions using an inverse method and chemical transport models with assimilated winds, J. Geophys. Res., 102, 28153-28168, 1997.

Maione, M., Arduini, J., Mangani, G., and Geniali, A.: Evaluation of an automatic sampling gas chromatographic-mass spectrometric instrument for continuous monitoring of trace anthropogenic gases, Int. J. Environ. Anal. Chem., 84, 241-253, 2004.

Maione, M., Giostra, U., Arduini, J., Belfiore, L., Furlani, F., Geniali, A., Mangania, G., Vollmer, M. K., and Reimann, S.: Localization of source regions of selected hydrofluorocarbons combining data collected at two European mountain stations, Sci. Total Environ., 391, 232-240, 2008.

Manning, A. J., Ryall, D. B., Derwent, R. G., Simmonds, P. G., and O'Doherty, S.: Estimating European emissions of ozonedepleting and greenhouse gases using observations and a modeling back-attribution technique, J. Geophys. Res., 108, 4405, 2003.

McCulloch, A., Midgley, P. M., and Ashford, P.: Releases of refrigerant gases (CFC-12, HCFC-22 and HFC-134a) to the atmosphere, Atmos. Environ., 37, 889-902, 2003.

McCulloch, A., Midgley, P. M., and Lindley, A. A.: Recent changes in the production and global atmospheric emissions of chlorodifluoromethane (HCFC-22), Atmos. Environ., 40, 936-942, 2006.

Menke, W.: Geophysical Data Analysis: Discrete Inverse Theory, Academic Press, Orlando, USA, 260 pp., 1984.

Miller, B. R., Weiss, R. F., Salameh, P. K., Tanhua, T., Greally, B. R., Mühle, J., and Simmonds, P. G.: Medusa: A sample preconcentration and GC/MS detector system for in situ measurements of atmospheric trace halocarbons, hydrocarbons, and sulfur compounds, Anal. Chem., 1536-1545, doi:10.1021/ac702084k, 2008.

Millet, D. B., E. L. Atlas, D. R. Blake, N. J. Blake, G. S. Diskin, et al. (2009): Halocarbon Emissions from the United States and Mexico and Their Global Warming Potential, Environ. Sci. Technol., 43, 1055-1060, 2009.

Mulquiney, J. E., Taylor, J. A., Jakeman, A. J., Norton, J. P., and Prinn, R. G.: A new inverse method for trace gas flux estimation: 2. Application to tropospheric CFCl3 fluxes, J. Geophys. Res., 103, 1429-1442, 1998

O’Doherty, S., Cunnold, D. M., Manning, A., Miller, B. R., Wang, R. H. J., et al.: Rapid growth of hydrofluorocarbon 134a and hydrochlorofluorocarbons 141b, 142b, and 22 from Advanced 
Global Atmospheric Gases Experiment (AGAGE) observations at Cape Grim, Tasmania, and Mace Head, Ireland, J. Geophys. Res., 109, D06310, doi:10.1029/2003JD004277, 2004.

Olivier, J. G. J. and Berdowski, J. J. M.: Global emissions sources and sinks, edited by: Berdowski, J., Guicherit, R. and Heij, B. J. (eds.) in: The Climate System, 33-78, A. A. Balkema Publishers/Swets \& Zeitlinger Publishers, Lisse, The Netherlands, ISBN: 90-5809-255-0.

Palmer, P. I., Jacob, D. J., Mickley, L. J., Blake, D. R., Sachse, G. W., et al.: Eastern Asian emissions of anthropogenic halocarbons deduced from aircraft concentration data, J. Geophys. Res., 108, 4753, doi:10.1029/2003JD003591, 2003.

Prinn, R. G., Weiss, R. F., Fraser, P. J., Simmonds, P. G., Cunnold, D. M., et al: A history of chemically and radiatively important gases in air deduced from ALE/GAGE/AGAGE, J. Geophys. Res., 105, 17751-17792, 2000.

Reimann, S., Schaub, D., Stemmler, K., Folini, D., Hill, M., Hofer, P., Buchmann, B., Simmonds, P. G., Greally, B. R., and O'Doherty, S.: Halogenated greenhouse gases at the Swiss high alpine site of Jungfraujoch (3580 m asl): Continuous measurements and their use for regional European source allocation, J. Geophys. Res., 109, D05307, doi:10.1029/2003JD003923, 2004.

Reimann, S., Vollmer, M. K., Folini, D., Steinbacher, M., Hill, M., Buchmann, B., Zander, R., and Mahieu, E.: Observations of long-lived anthropogenic halocarbons at the high-Alpine site of Jungfraujoch (Switzerland) for assessment of trends and European sources, Sci. Total Environ., 391, 223-231, 2008.

Seibert, P.: Inverse modelling of sulfur emissions in Europe based on trajectories, in: Inverse Methods in Global Biogeochemical Cycles, edited by: Kasibhatla, P., Heimann, M., Rayner, P., Mahowald, N., Prinn, R. G., and Hartley, D. E., 147-154, Geophysical Monograph 114, American Geophysical Union, ISBN:087590-097-6, 2000.

Seibert, P.: Inverse modelling with a Lagrangian particle dispersion model: application to point releases over limited time intervals, In: Air Pollution Modeling and its Application XIV, edited by: Schiermeier, F. A. and Gryning, S.-E., Kluwer Academic Publ., 381-389, 2001.

Seibert, P. and Frank, A.: Source-receptor matrix calculation with a Lagrangian particle dispersion model in backward mode, Atmos. Chem. Phys., 4, 51-63, 2004, http://www.atmos-chem-phys.net/4/51/2004/.

Seibert, P. and Skomorowski, P.: Untersuchung der orographischen Besonderheiten der Probennahmestellen Schauinsland und Freiburg und deren Auswirkungen auf die Genauigkeit von adjungierten atmosphärischen Ausbreitungsrechnungen, Schriftenreihe Reaktorsicherheit und Strahlenschutz, BMU-2008-713, 194 pp., http://www.bmu.de/41875, 2008.
Simmonds, P. G., Odoherty, S., Nickless, G., Sturrock, G. A., Swaby, R., Knight, P., Ricketts, J., Woffendin, G., and Smith, R.: Automated Gas-Chromatograph Mass-Spectrometer for Routine Atmospheric Field-Measurements of the Cfc Replacement Compounds, the Hydrofluorocarbons and Hydrochlorofluorocarbons, Anal. Chem., 67, 717-723, 1995.

Stohl, A., Hittenberger, M., and Wotawa, G.: Validation of the Lagrangian particle dispersion model FLEXPART against large scale tracer experiment data, Atmos. Environ., 32, 4245-4264, 1998.

Stohl, A. and Thomson, D. J.: A density correction for Lagrangian particle dispersion models, Bound.-Lay. Meteorol., 90, 155-167, 1999.

Stohl, A., S. Eckhardt, C. Forster, P. James, and N. Spichtinger: On the pathways and timescales of intercontinental air pollution transport, J. Geophys. Res., 107, 4684, doi:10.1029/2001JD001396, 2002.

Stohl, A., Forster, C. Eckhardt, S., Spichtinger, N., Huntrieser, H., Heland, J., Schlager, H., Wilhelm, S., Arnold, F., and Cooper, O.: A backward modeling study of intercontinental pollution transport using aircraft measurements, J. Geophys. Res., 108, 4370, doi:10.1029/2002JD002862, 2003.

Stohl, A., Forster, C., Frank, A., Seibert, P., and Wotawa, G.: Technical note: The Lagrangian particle dispersion model FLEXPART version 6.2., Atmos. Chem. Phys., 5, 2461-2474, 2005, http://www.atmos-chem-phys.net/5/2461/2005/.

Stohl, A., Berg, T., Burkhart, J. F., Fjæraa, A. M., Forster, et al.: Arctic smoke - record high air pollution levels in the European Arctic due to agricultural fires in Eastern Europe, Atmos. Chem. Phys., 7, 511-534, 2007, http://www.atmos-chem-phys.net/7/511/2007/.

Technology and Economic Assessment Panel: Supplement to the IPCC/TEAP report, United Nations Environment Programme, Nairobi, ISBN: 92-807-2733-8, 2005.

United Nations Environment Programme (UNEP): Production and Consumption of Ozone Depleting Substances under the Montreal Protocol 1986-2004, Ozone Secretariat, UNEP, Nairobi, Kenya, 75 pp., 2005.

Wotawa, G., De Geer, L.-E., Denier, P., Kalinowski, M., Toivonen, H., D’ Amours, R., Desiato, F., Issartel, J.-P., Langer, M., Seibert, P., Frank, A., Sloan, C., and Yamazawa, H.: Atmospheric transport modelling in support of CTBT verification - overview and basic concepts, Atmos. Environ., 37, 1565-1573, 2003.

Yokouchi, Y., Taguchi, S., Saito, T., Tohjima, Y., Tanimoto, H., and Mukai, H.: High-frequency measurements of HFCs at a remote site in east Asia and their implications for Chinese emissions, Geophys. Res. Lett., 33, L21814, doi:10.1029/2006GL026403, 2006. 